\title{
Análise da Microdureza e Morfologia Superficial da Dentina de Dentes Decíduos Biomodificada com Quitosana após Indução de Lesão de Cárie Dentária Artificial
}

\author{
Tese apresentada à Faculdade de Odontologia de \\ Ribeirão Preto da Universidade de São Paulo, para \\ obtenção do Título de Doutora em Ciências. \\ Área de Concentração: Odontopediatria \\ Orientadora: Profa. Dra. Silmara Aparecida Milori Corona
}

Ribeirão Preto 


\section{AUTORIZAÇÃO PARA REPRODUÇÃO}

Autorizo para reprodução e divulgação total ou parcial deste trabalho por qualquer meio convencional ou eletrônico, para fins de estudo e pesquisa, desde que citada a fonte.

FICHA CATALOGRÁFICA

Lorencetti-Silva, Francine

Análise da microdureza e morfologia superficial da dentina de dentes decíduos biomodificada com quitosana após indução de lesão de cárie dentária artificial. Ribeirão Preto, 2018.

86p.: il.; $30 \mathrm{~cm}$

Tese de Doutorado apresentada à Faculdade de Odontologia de Ribeirão Preto/USP - Área de Concentração: Odontopediatria.

Orientadora: Corona, Silmara Aparecida Milori Corona

1. Dente Decíduo 2. Quitosana 3. Odontologia Minimamente Invasiva 4. Dentina 


\section{FolHA DE APROVAÇÃo}

Lorencetti-Silva, F. Análise da Microdureza e Morfologia Superficial da Dentina de Dentes Decíduos Biomodificada com Quitosana após Indução de Lesão de Cárie Dentária Artificial

Tese apresentada à Faculdade de Odontologia de Ribeirão Preto da Universidade de São Paulo, para obtenção do Título de Doutora em Ciências

Área de Concentração: Odontopediatria

Data da defesa:

\section{Banca Examinadora}

Prof. Dr.

Instituição:

Julgamento:

Assinatura:

Prof. Dr.

Instituição:

Julgamento:

Assinatura:

Prof. Dr.

Instituição:

Julgamento:

Assinatura: 



\section{Dados CuRriculares}

\section{Francine Lorencetti da Silva Campioni}

Nascimento 20 de dezembro de 1990 - Jardinópolis/SP

Filiação Marcos Elísio da Silva

Carmem Sílvia Lorencetti da Silva

2009-2012 Curso de Graduação (Universidade de São Paulo)

Faculdade de Odontologia de Ribeirão Preto

Iniciação científica: Avaliação radiográfica digital das estruturas periodontais, dentina e polpa dentária de crianças com bruxismo do sono.

Orientadora: Profa. Dra. Kranya Victoria Díaz-Serrano

2013-2014 Curso de Aperfeiçoamento

Atendimento Odontológicos a Pacientes

Especiais (Universidade de São Paulo)

Faculdade de Odontologia de Ribeirão Preto

2013-2015 Curso de Especialização em Odontopediatria

Associação odontológica de Ribeirão Preto - AORP

2013-2015 Curso de Pós-Graduação em Odontopediatria

Mestrado (Universidade de São Paulo)

Faculdade de Odontologia de Ribeirão Preto

2015-2018 Curso de Pós-Graduação em Odontopediatria

Doutorado (Universidade de São Paulo)

Faculdade de Odontologia de Ribeirão Preto

2017 -Atual Professora Adjunta Nível I (Universidade de Rio Verde) Faculdade de Odontologia de Rio Verde 


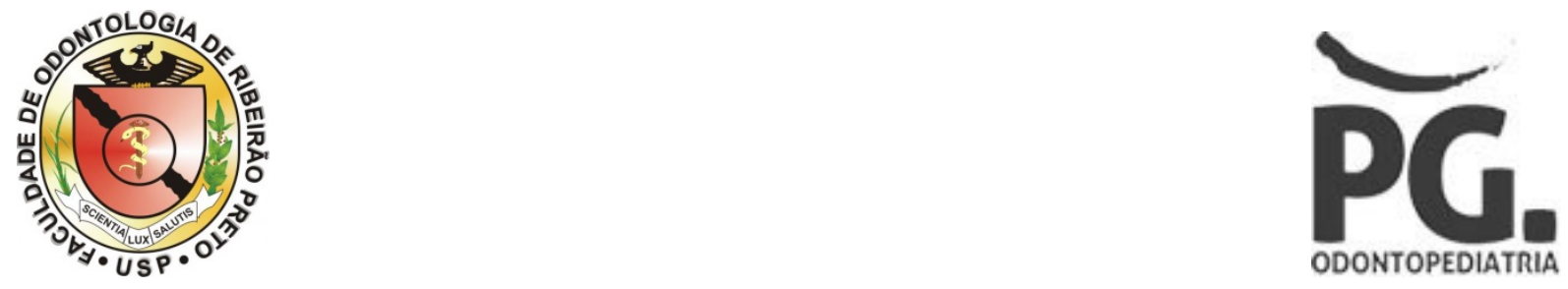

"O presente trabalho foi realizado com apoio da Coordenação de Aperfeiçoamento de Pessoal de Nível Superior - Brasil (CAPES) - Código de Financiamento 001." 

Dedicatória 



\section{DEDICATÓRIA}

A Deus, pelas inúmeras bênçãos e alegrias que têm colocado em meu caminho. Sou grata a tudo que Tem proporcionado em minha vida... Obrigada por todas as alegrias e vitórias a mim concedidas e por sempre colocar em meu caminho pessoas especiais.

\section{A meus pais, Carmem Silvia Lorencetti da Silva e Marcos Elísio da Silva pela} dedicação diăria, por todas as vezes que me proporcionaram condições para seguir em frente. O carinho e o amor a mim atribuídos são imensuráveis e incapazes de serem descritos em simples palavras.

A meu marido, Bruno Campioni. Bruno, iá há algum tempo você tem caminhado junto comigo. Tem enfrentado comigo minhas batalhas, minhas dúvidas e compartilhado minhas vitórias. Obrigada por tudo que fez e faz por mim e por, principalmente, me impulsionar e acreditar no meu potencial. Você me transformou em uma pessoa mais forte e, sem dúvida, muito mais capaz.

\section{Aos meus avós, Francisco da Silva (in memorian) e Maria Biancullo da Silva (in} memorian). Sem dúvida alguma vocês foram minha fonte maior de inspiração e cuidado. Cuidarei de vocês para sempre, pois estaremos sempre juntos, lado a lado. Meu coração se enche de alegria ao lembrar de vocês. Sinto saudades, mas conforto por saber que vocês cumpriram sua missão tão bem e deixaram um legado de amor, respeito, carinho e cuidado. Obrigada por todos os anos de convivência e muito aprendizado.

Aos meus avós, Raul Lorencetti e Maria Celina Magiollo Lorencetti. Todos os dias, tenho a certeza que terei a honra de encontrar o seu sorriso e seu carinho assim que eu chegar para uma visita ou uma conversa. Com vocês aprendi o maior ensinamento da vida: é preciso compartilhar o amor e a amizade, é preciso respeitar o outro para assim ser respeitado. Sorrir é sempre a melhor solução para qualquer adversidade, mesmo nos casos de maior dor. 

Agradecimento Especial 



\section{AGRADECIMENTO ESPECIAL}

À minha querida orientadora, Profa. Dra. Silmara Aparecida Milori Corona. Professora tenho na senhora um exemplo de pessoa e profissional. Obrigada por todas as incriveis oportunidades que me permitiu viver e por sempre me guiar de forma tão leve. Aprendi que para adquirir conhecimento é preciso ter respeito e dedicação. É preciso compartilhar, ler, discutir, buscar, mas acima de tudo, é preciso paciência, motivação e alegria. Sim, muita alegria! Quando em tudo o que fazemos colocamos uma dose diária de alegria as coisas acontecem de forma muito mais prazerosa e muito mais precisa. Obrigada professora pelas risadas, oportunidades, ensinamentos e conselhos. Obrigada por acreditar tanto em mim e no meu potencial. Sinto-me extremamente honrada por ter sido sua orientada...

Se pensarmos pequeno, coisas pequenas teremos...

Mas se desejarmos fortemente o melhor e principalmente lutarmos pelo melhor, o melhor vai se instalar em nossa vida.

Porque sou do tamanho daquilo que vejo, e não do tamanho da minha altura. 

Agradecimentos 



\section{AGRADECIMENTOS}

À Faculdade de Odontologia de Ribeirão Preto da Universidade de São Paulo, na pessoa da atual diretora Profa. Dra. Léa Assed Bezerra da Silva e à Coordenação do Curso de Pós-Graduação em Odontopediatria da Faculdade de Odontologia de Ribeirão Preto da Universidade de São Paulo, na pessoa da Profa. Dra . Raquel Assed Bezerra Segato e do ViceCoordenador Prof. Dr. Manoel Damião de Souza Neto.

Ao Prof. Dr. Francisco Wanderley Garcia de Paula e Silva. Francisco, tenho plena convicção de que só nos transformamos à medida que refletimos sobre nossa própria condição e nos permitimos mudar. A mudança só é possível a partir do momento que buscamos algo novo e aprendemos, quer seja com nossos acertos quer seja com nossos erros. Obrigada por todos os desafios que você me impôs durante o período que fui sua orientada, mas acima de tudo, obrigada por me permitir superar meus próprios limites e descobrir que sou capaz. Terei você como meu exemplo, sempre.

Ao Prof. Dr. Paulo Nelson-Filho è à Profa. Dra. Alexandra Mussolino de Queiroz. Ser Mestre exige muito mais do que o simples conhecimento. Exige o saber transmitir, o saber cativar. Tornei-me apaixonada pela Odontopediatria pela forma tão linda que vocês me ensinaram. Obrigada por sempre estarem ao meu lado, mas principalmente, por me mostrarem o caminho a seguir. Espero um dia conseguir representar a Odontopediatria ao menos um pouco o que vocês representam a mim

Ao corpo docente do Departamento de Clínica Infantil da Faculdade de Odontologia de Ribeirão Preto da Universidade de São Paulo, Profa. Dra. Léa Assed Bezerra da Silva, Profa. Dra. Aldevina Campos de Freitas, Prof. Dr. Paulo Nelson-Filho, Profa. Dra. Alexandra Mussolino de Queiroz, Prof. Dr. Fabrício Kitazono de Carvalho, Profa. Dra. Kranya Victória Díaz-Serrano, Profa. Dra. Maria Cristina Borsatto, Profa. Dra. Raquel Assed Bezerra Segato, Profa. Dra. Andiara de Rossi Daldegan, Profa. Dra. Mírian Aiko Nakane Matsumoto, Profa. Dra. Maria Bernadete Sasso Stuani, Prof. Dr. José Tarcísio 
Lima Ferreira, Prof. Dr. Adilson Thomazinho, Prof. Dr. Fäbio Lourenço Romano e Profa. Dra. Maria da Conceição Pereira Saraiva. Obrigada pelas inúmeras vezes que se disponibilizaram em me auxiliar de alguma forma e por todo conhecimento transmitido.

A Ana Paula Macedo e Adriana de Mattos Gonçalves da Silva, responsáveis técnicas no Departamento de Materiais Dentários e Prótese da Faculdade de Odontologia de Ribeirão Preto da Universidade de São Paulo por todo auxílio, disponibilidade e carinho comigo. Obrigada pelas inúmeras vezes que me receberam quer seja durante a etapa experimental quer seja durante a análise dos dados.

A Profa. Dra. Renata Cristina Silviera R. Ferracioli pela prontidão em disponibilizar equipamento para desenvolvimento do presente estudo.

Às minhas querida amigas Mariana de Oliveira Daltoé, Juliana Arid e Carolina Maschietto Puccineli. Sempre tive a certeza que não basta viver momentos que não possam ser compartilhados. Tive a honra de caminhar junto com vocês desde o início e tenho muito orgulho do que nos tornamos e como nos transformamos. Obrigada por estarem ao meu lado sempre...por compartilharem tudo comigo e, principalmente, por manterem nossa amizade sólida e forte, independente da distância que nos separa.

A minha querida amiga Fabiana Almeida Curylofo Zotti. Fabi, que presente Deus me enviou quando nos conhecemos. Tive em você a imagem da irmã conselheira, amiga, confidente e parceira. Obrigada por permitir aprender junto com sua paciência, sua inteligência e seu carisma. Você será pra sempre minha grande e querida amiga. Obrigada por tudo!

Às minhas amigas Fernanda Vicioni Marques e Ana Carolina Fumes Morgado. Juntas rimos muito, compartilhamos nossos momentos de maior alegria, mas também nos auxiliamos e aconselhamos umas às outras. Essa convivência nos fez crescer e aprender que quando partilhamos nossas fraquezas e conquistas, nos tornamos muito mais fortes. Muito obrigada, meninas... 
Aos amigos e amigas que a Pós-Graduação me enviou de presente Sofia Sampaio Meireles de Souza, Marilia Moreira, Driely Barreiros, Patrícia Maria Monteiro, Sara Silva de Oliveira, Leonardo Gontijo Matos, Daniele Lucca Longo, Denise de Souza Matos, Katharina Morant Holanda de Oliveira, Mariana Alencar Namezio, Priscilla Coutinho Romualdo, Danielly Cunha Araújo Ferreira, Daniela Barroso, Lídia Hidalgo, Marina Moscardini Vilela, Paula Regina Ávila Silvano, Maria Gabriela Flores Bracho, Elaine Machado Pingueiro, Larissa Nogueira Soares Ribeiro, Mariele Andrade, Claudia Carpio, Thaîs Aparecida Xavier, Nicole Gonçalves Lima, Raquel Morelli, Letícia Sgarbi Pinto, Arthur Cunha, Guido Artemio Marañon Vasquez, Marjorie Homori, José Guilherme Naves, Gabriela Solano, Isabela Ziotti, Mirian Saavedra, Reginaldo Dias Neto, Késsia Mesquita Guimarães, Maria Cecîlia Gorita e Fernanda Liévena pelos momentos compartilhados. Obrigada pela adorável convivência!

Aos meus queridos amigos da Turma LXXXIV da Faculdade de Odontologia de Ribeirão Preto da Universidade de São Paulo. Tudo isso só foi possível porque há quase dez anos fiz uma escolha: Ser dentista. Aprendi, junto com vocês, que ser dentista não basta, pois nada faz sentido se estamos sozinhos. É preciso ser dentista com o olhar voltado para o outro, para suas limitações, fraquezas e necessidades...compartilhar nos transforma, nos motiva e transforma nossa rotina em felicidade. Eterna e fraterna 84, muito obrigada!!!

Aos funcionários Patrícia Marchi e Reginaldo Santana do Departamento de Odontologia Restauradora da Faculdade de Odontologia de Rib

eirão Preto da Universidade de São Paulo por toda ajuda e agradável convivência.

Aos funcionários do Departamento de Clínica Infantil da Faculdade de Odontologia de Ribeirão Preto da Universidade de São Paulo, Marîlia Pacífico Lucisano, Carolina Paes Torres Mantovani Nilza Letícia Magalhães, Marco Antônio dos Santos, Fătima Aparecida Jacinto Daniel, Filomena Lelli Placciti, Matheus Morelli Zanela, Micheli Cristina Leite Rovanholo, Rosemary Alves, Vera do Nascimento Scandelai, Renata Cristina Rosa, Fâtima Aparecida Rizoli. Conviver com cada um de vocês foi de grande importância para o meu crescimento como pessoa. Tenham certeza que todas as vezes que cada um de 
vocês me dirigiu atenção ou simplesmente me ouviu contribui de forma significativa para a concretização de mais esta etapa. Cada "bom dia", cada gargal hada compartilhada e, até mesmo, cada consolo que recebi de vocês foi capaz de me transformar na pessoa que sou hoje. Agradeço diariamente por ter vocês como amigos e presença em meus dias. Adoro vocês!

Aos funcionários da Seção de Pós-Graduação da Faculdade de Odontologia de Ribeirão Preto da Universidade de São Paulo Mary Possani e Carlos Feitosa dos Santos pela disposição e atenção para comigo.

Aos meus queridos alunos da Universidade de Rio Verde. Sinto-me honrada por fazer parte da formação acadêmica de cada um de vocês. Todos os dias deixo minha casa com a missão mais incrivel e gratificante que existe: a de transformar pessoas e despertar o potencial de cada um. Saibam que sou imensamente grata a cada um de vocês, pois vocês também me transformam todos os dias no melhor que eu posso ser.

Aos meus amigos da Universidade de Rio Verde, professores e funcionários. Obrigada a todos os amigos professores que dividem comigo a incrivel jornada da docência e a todos os funcionários pelo auxîlio diário. Obrigada por compartilharem comigo seu conhecimento, por se mostrarem sempre dispostos, mas especialmente, por me proporcionarem sua amizade.

À CAPES (Coordenação de Aperfeiçoamento de Pessoal de Nivel Superior), pelo apoio financeiro concedido para o desenvolvimento desta pesquisa.

A todos que tornaram possivel a concretização desta tese. Obrigada! 
Resumo 



\section{RESUMO}

Lorencetti-Silva, F. Análise da microdureza e morfologia superficial da dentina de dentes decíduos biomodificada com quitosana após indução de lesão de cárie dentária artificial. 2018. 86f. Tese (Doutorado) - Faculdade de Odontologia de Ribeirão Preto, Universidade de São Paulo, Ribeirão Preto, 2018.

Quitosana é um biopolímero natural obtido a partir da desacetilação de quitina. Embora a quitosana já seja utilizada na Odontologia, seu papel sobre o substrato dentinário de dentes decíduos não está bem elucidado. Portanto, o objetivo do presente estudo foi avaliar o papel da incorporação do gel de quitosana a 2,5 \% na dentina de dentes decíduos afetada por lesão de cárie. Dentes decíduos extraídos foram coletados e submetidos à indução de lesão de cárie artificial. Após teste de microdureza inicial $(n=28)$, os dentes foram estratificados para receber gel de quitosana a 2,5\%. A superfície dentinária hígida $(n=3)$, dentina desmineralizada $(n=3)$ e dentina biomodificada com gel de quitosana a 2,5\% ( $n=3)$ foram submetidas à Espectroscopia de Energia Dispersiva de Raio-X (EDS) e Microscopia Eletrônica de Varredura (MEV). O teste de microdureza também foi realizado após a indução de lesão de cárie artificial e após a biomodificação da dentina. Os dados foram avaliados usando o teste paramétrico one-way ANOVA para medidas repetidas. A análise dos dados para EDS foi efetuada por meio de teste não paramétrico de Kruskal-Wallis seguido pelo ajuste dos valores de significância pela correção de Bonferroni para múltiplos testes, bem como por meio de estatística descritiva dos dados obtidos através da fórmula: Variável de estudo - controle/ controle $\times 100$. A biomodificação da dentina não alterou a microdureza da superfície dentinária $(p=0,339)$. A porcentagem atômica de cálcio revelou diferenças estatisticamente significantes antre a dentina hígida e biomodificada com quitosana $(p<0.022)$, assim como a porcentagem atômica de fósforo que se mostrou superior no grupo que sofreu a biomodificação. A MEV revelou um expressivonúmero de túbulos dentinários obliterados, porém com maior diâmetro. As imagens topográficas revelaram, ainda, uma superfície lisa e regular após a biomodificação. Embora a aplicação do gel de quitosana a 2,5\% na dentina parcialmente desmineralizada em dentes decíduos não foi capaz de aumentar o valor de microdureza, a biomodificação gerou uma superfície dentinária apropriada para procedimentos restauradores adesivos.

Palavras-chave: Dentição decídua, Quitosana, Odontologia Minimamente Invasiva, Dentina 

Abstract 



\begin{abstract}
Lorencetti-Silva, F. Microhardness and surface morphology dentin analysis in primary teeth biomodified with chitosan after artificial caries lesion induction. 2018. 86f. Tese (Doutorado) - Faculdade de Odontologia de Ribeirão Preto, Universidade de São Paulo, Ribeirão Preto, 2018.

Chitosan is a natural biopolymer obtained from chitin deacetylation. Although chitosan is already used in dentistry, this role on the primary teeth dentin substrate is not well elucidated. So, the aim to this study was to evaluate the role of the $2.5 \%$ chitosan gel incorporation in primary caries-affected dentin teeth. Extracted primary teeth were collected and submitted to artificial caries induction. Teeth were stratified to receive $2.5 \%$ chitosan gel after dentin microhardness initial test $(n=28)$. Healthy dentin $(n=3)$, demineralized dentin $(n=3)$ and biomodified dentin with $2.5 \%$ chitosan gel $(n=3)$ were submitted to Energy Dispersive X-ray Spectroscopy (EDS) and Scanning Electron Microscopy (SEM). Microhardness Test was performed too after artificial caries induction and after dentin biomodification. Data were evaluated using one-way ANOVA repeated measures parametric test. Data analysis for EDS was performed using non-parametric Kruskal-Wallis test followed by adjustment of significance values by Bonferroni correction for multiple tests, as well as by means of descriptive statistics of the data obtained using the formula: Study variable control/control $\times 100$. Dentin biomodification did not alter the subsurface microhardness of dentin $(p=0,339)$. The calcium atomic percentage showed statistically significant differences between healthy and biomodificated dentin $(p<0.022)$ and too presented superior phosphorus atomic percentage. SEM revealed expressive number of dentinal tubules obliterated, but a larger diameter. Topographic images revealed a smooth and regular surface in biomodified dentin. Although $2.5 \%$ chitosan gel application on partially demineralized dentin in primary teeth was not able to increase microhardness, the biomodification generated an appropriate dentin surface for adhesive restorative procedures.
\end{abstract}

Keywords: Primary teeth, Chitosan, Minimally Invasive Dentistry, Dentin 

Sumário 

SUMÁRIO

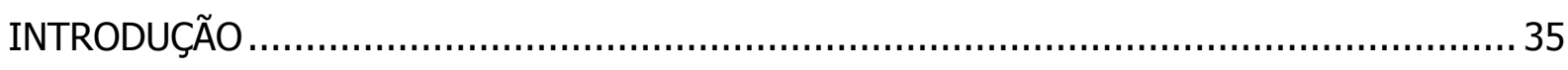

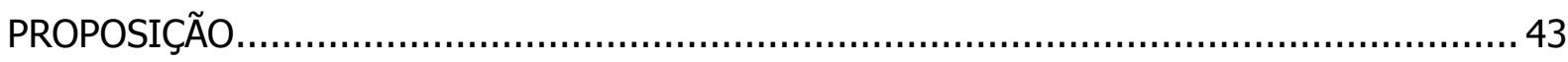

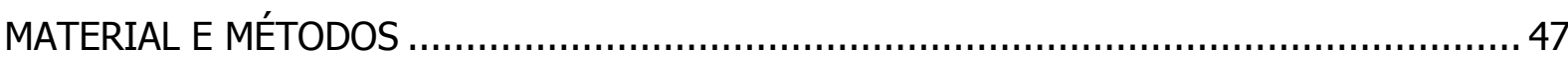

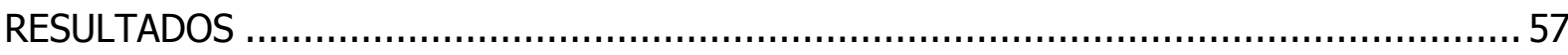

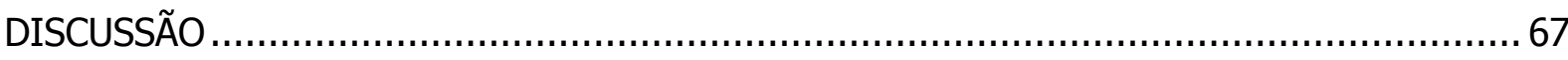

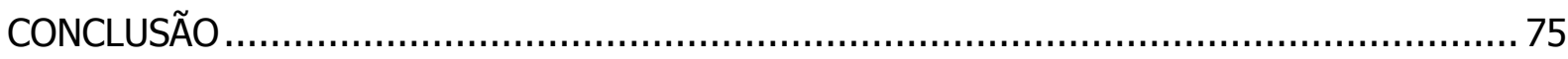

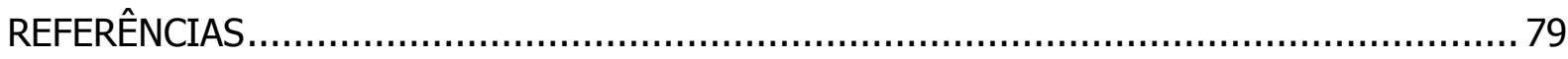



Introdução 



\section{İNTRODUÇão}

A cárie dentária continua a ser a doença bucal mais prevalente na população infantil a nível mundial, apesar do declínio em sua prevalência nos últimos anos (Benjamin, 2010; Philip et al., 2018b). No início dos anos 60 foi conceituada por Paul Keys como uma doença infecciosa, transmissível e de caráter multifatorial, cuja etiologia era associada à uma tríade bem definida: presença de micro-organismos, dentes susceptíveis e presença de substratos fermentáveis, cuja atuação conjunta em mesma intensidade induziam o processo de instalação e desenvolvimento da doença citada (Keys, 1962; Giacam et al., 2017). Esse conceito reducionista acerca da etiologia da cárie dentária foi modificado por Newbrum na década de 80, o qual apresentou a cárie dentária como sendo resultante da tríade anteriormente citada associada ao fator tempo, por se tratar de uma doença crônica, cujos sinais e sintomas na superfície dentária levam tempo para serem detectados clinicamente (Newbrum, 1983; Ferreira-Nóbilo et al., 2014).

Apesar do estabelecimento dos fatores causais por Keys (1962) e Newbrum (1983) é importante destacar que a cárie dentária é considerada uma doença de natureza multifatorial, cuja causalidade não é associada à adoção de medidas preventivas simplistas (Philip et al., 2018a). Assim sendo, a cárie dentária deve ser entendida como uma das doenças multifatoriais crônicas mais comuns na população mundial, cuja susceptibilidade é mantida durante toda vida a depender de vários fatores de risco a ela associados, o que inclui fatores ambientais (nutrição, higiene bucal, uso de flúor e grau de colonização de bactérias cariogênicas, características culturais, estilo de vida e status socioeconômico), fatores de risco relacionados ao hospedeiro (fluxo e composição da saliva, capacidade tamponante, posição dos dentes, características superficiais do esmalte dentário e profundidade das fossas e fissuras dos dentes posteriores) e fatores hereditários (Lin et al., 2018).

Portanto, a cárie dentária deve ser entendida como uma doença causada por uma mudança ecológica do biofilme dentário, impulsionada pela oferta frequente de carboidratos fermentáveis advindos da dieta, cujo resultado é o shift microbiano de uma população balanceada de micro-organismos de baixa cariogenicidade para uma população microbiológica de alta cariogenicidade, acidogênica e acidúrica, o que 
culmina na perda mineral do tecido duro dentário e gera a lesão cariosa (Fejerskov e Larsen 2015; Innes et al., 2016). Pragmaticamente, a cárie deve ser conceituada, como uma doença biofilme-açúcar-dependente, de caráter multifatorial, que envolve fatores necessários (acúmulo de biofilme), fatores modificadores - tanto biológicos quanto sociais (como eduação, classe social comportamento e atitudes), e fatores determinantes (exposição a açúcares e flúor) para que haja instalação e desenvolvimento da doença propriamente dita (Fejerskov, 2004; Cury et al., 2010; Ferreira-Nóbilo et al., 2014).

Portanto, como se pôde perceber, os conceitos relacionados à etiologia da cárie dental evoluíram ao longo das décadas (Philip et al., 2018b) e, portanto, seu manejo deve refletir o dinamismo da doença (Machiulskiene e Carvalho, 2018).

Assim sendo, a compreensão acerca da doença cárie e sua patogênese fizeram com que as estratégias de remoção do tecido cariado mudassem de maneira tal que a remoção total da dentina cariada de uma cavidade não seja mais necessária, pois a filosofia contemporânea de manejo da lesão cariosa emprega o tratamento voltado para a paralização da doença, impedindo sua atividade e preservando o tecido dentário sadio e a vitalidade pulpar (Schwendicke, 2017).

Por muito tempo o tratamento restaurador preconizou preparos cavitários extensos por acreditar que assim os micro-organismos eram removidos de maneira definitiva e eficaz, além de esta conformação auxiliar na retenção mecânica do material restaurador, conceitos estes não mais difundidos graças à incorporação de materiais adesivos na área odontológica e também à melhor compreensão acerca da doença cárie (Banerjee et al., 2017).

O conceito de Odontologia Minimamente Invasiva adota um perfil filosófico que integra a prevenção, a remineralização e a intervenção mínima para inserção de restaurações, de modo a utilizar-se de abordagens cirúrgicas menos invasivas, removendo minimamente os tecidos dentais saudáveis (Mm et al., 2014).

Dessa forma, a remoção seletiva de tecido cariado em dentes decíduos têm se mostrado uma técnica vantajosa e constitui uma alternativa definitiva de tratamento restaurador, haja visto que este tipo de tratamento inativa as lesões de cárie e reduz os níveis de micro-organismos cariogênicos no tecido dentinário, ao mesmo tempo em que reduz o risco de exposição do tecido pulpar e impede a 
progressão da atividade cariogênica na lesão. (O'Connell, 2012; Ribeiro et al., 2012; Elhennawy et al., 2018).

Obviamente que há diferenças morfológicas e estruturais no tocante ao substrato dentinário a depender se a dentina é classificada como infectada ou afetada pela lesão de cárie (Costa et al., 2017). A camada de dentina infectada apresenta superfície necrótica com um grande número de bactérias, sendo completamente desmineralizada e com estrutura colágena desorganizada, cuja presença de presença de tecido desmineralizado está associada à zona necrótica (Macedo et al., 2009; Banerjee et al., 2010; Almeida Neves et al., 2011; Banerjee et al., 2013; Silva Júnior et al., 2015; Costa et al., 2017). Em contrapartida, a dentina afetada apresenta pouca mudança estrutural no que diz respeito à conformação de colágeno e, portanto, é passível de remineralização, apresentando pouca ou nenhuma bactéria, cujo contraste com a dentina hígida se dá por meio de precipitados mineralizados no interior dos túbulos dentinários (Almeida Neves et al., 2011; Mobarak et al., 2012; Banerjee et al., 2013; Silva Júnior et al., 2015; Costa et al., 2017).

Dentro deste contexto, deve-se deixar claro que apenas a dentina infectada precisa ser removida para que se concretize o processo de preparo cavitário, onde a dentina afetada, passível de remineralização a partir de um procedimento restaurador bem realizado, pode permanecer, de maneira a evitar escavação de dentina próximo à polpa, haja visto que a remoção parcial do tecido cariado é limitado à parede pulpar e paredes axiais (Thompson et al., 2008; Frencken et al., 2012; Innes et al., 2016).

As evidências científicas suportam a ideia de que a mínima intervenção das lesões de cárie preserva o tecido dental ao mesmo tempo em que mantém a integridade da polpa e retarda a inserção do indivíduo em um ciclo restaurador destrutivo (Benerjee et al., 2017). Portanto, é de se compreender que a remoção seletiva do tecido cariado se mostra preferível quando comparada à remoção completa do mesmo, de maneira a reduzir os riscos de exposição pulpar (Thompson et al., 2008), o que coloca o uso de técnicas minimamente invasivas de remoção de tecido cariado muito importante (Casagrande et al., 2016). 
É fato que a dentina de dentes decíduos difere dos dentes permanentes, onde foi possível observar que há uma redução gradual nos valores da dureza e do módulo de elasticidade da dentina à medida que se aproxima do tecido pulpar (Angker, et al., 2003). É importante ressaltar que as diferenças regionais no tocante à microdureza na superfície dentinária podem alterar a distribuição das tensões ao longo da interface, e assim, determinar a localização de falhas (Fuentes et al., 2003). No entanto, é fato que a dureza do tecido dentinário é dependente diretamente do seu grau de mineralização e, quando se trata de dentina cariada, os valores da dureza também estão na dependência no estágio de progressão da doença, o que configura uma redução nestes valores nos períodos iniciais da lesão (Benerjee et al., 1999). Apesar disso, é importante ressaltar que as porções orgânica e inorgânica da dentina configuram um quadro estrutural de fundamental importância para manutenção da integridade mecânica dos dentes (Kishen et al., 2006; Kishen et al., 2016), e portanto, melhorar as propriedades mecânicas da estrutura dentinária a partir destes componentes, se revela pertinente.

Diante de todo o exposto, fica claro que a biomodificação da dentina reforça a estrutura dentinária e altera a bioquímica local, bem como suas propriedades mecânicas (Bedran-Russo et al., 2014). Por isso, diversos estudos têm sugerido diferentes abordagens para melhorar o potencial de adesão das fibras colágenas da dentina, incluindo a utilização de biopolímeros, como a quitosana (Fawzy et al., 2013).

A quitosana foi identificada pela primeira vez em 1811 em cogumelos pelo francês Henri Braconnot sob a forma de quitina e, desde então, pesquisas têm sido conduzidas com a mesma (Patrulea et al., 2015; Periayah et al., 2016). Este biopolímero é quimicamente categorizado como um aminopolissacarídeo linear, cuja composição é formada por glicosamina e unidades de $\mathrm{N}$-acetil glucosamina unidas por meio de ligações glicosídicas $\beta(1-4)$ após a N-desacetilação da quitina, a qual constitui seu polímero original (Patrulea et al., 2015). A quitina, também denominada poli $(\beta-(1 \rightarrow 4)-N$-acetil-d-glucosamina), é um polissacarídeo natural encontrado na forma de microfibrilas cristalinas ordenadas, quando em estado nativo, no exoesqueleto de crustáceos, insetos e na parede celular de fungos e leveduras (Rinaudo, 2006; Ifuku, 2014; Younes e Rinaudo, 2015). É o segundo biopolímero 
mais abundante na natureza, porém, muitas vezes descartado por não ser solúvel em qualquer solvente e, assim, precipitar imediatamente, uma vez que apresenta estrutura linear, alta cristalinidade e organização sob a forma de nanofibras (Ifuku, 2014).

Como explicitado anteriormente, a quitosana é um polímero catiônico obtido a partir da desacetilação parcial alcalina de quitina, normalmente derivada de crustáceos, mas também encontrada no exoesqueleto de artrópodes e na parede celular de fungos e leveduras (Elsaka e Elnaghy, 2012; Younes e Rinaudo, 2015; Ahmed e Aljaeid, 2016). Apesar de constituir uma base fraca insolúvel em água e em solventes orgânicos, a quitosana torna-se solúvel quando diluída em soluções ácidas aquosas de ácido acético, cítrico, tartárico e fosfórico (Chandy e Sharma, 1990; Ahmed e Aljaeid, 2016;) e reúne características biológicas de grande importância, de modo a destacar seu amplo espectro de ação antibacteriana (bactérias Grampositivas e Gram-negativas) e sua ação antibiofilme relacionadas, em parte, à carga catiônica deste composto, o qual interage com a superfície bacteriana carregada negativamente e reduz a permeabilidade da célula bacteriana, o que culmina na morte celular, além de reunir outras carcaterísticas importantes, como a biocompatibilidade e mucoadesão ( $\mathrm{Hu}$ et al., 2007; Xia et al., 2011; Elsaka e Elnaghy, 2012; Debnath et al., 2017).

Quando utilizada em sistemas scaffolds, a quitosana melhora a resistência mecânica, a taxa de biodegradação e a capacidade de proliferação celular, além das propriedades antibacteriana, homeostática e mucoadesiva, podendo atuar também como um agente acelerador do processo de cicatrização (Tangsadthakun et al., 2007; Patrulea et al., 2015). Quando aplicada diretamente sobre a dentina, este composto tem a capacidade de agir sobre o biofilme, desagregando-o, além de servir como agente quelante na dentina radicular (Del Carpio-Perochena et al., 2015). De fato, a modificação do substrato dentinário com quitosana associada à riboflavina aumenta as propriedades mecânicas e melhora a estabilidade mecânica contra a degradação hidrolítica e colagenolítica (Fawzi et al., 2013).

Dessa forma, e diante de todo o exposto, a quitosana representa um biopolímero de grande potencial de aplicação como biomaterial, graças às suas propriedades biocompatíveis e funcionais citadas (Arnaud et al., 2010). 
O papel exclusivo da quitosana sobre o substrato dentinário, porém, não está bem elucidado. E mais, o papel deste composto na microdureza do substrato dentinário em dentes decíduos permanece completamente desconhecido.

Assim, diante do exposto, torna-se necessário avaliar o papel da incorporação do biopolímero quitosana na dentina afetada por cárie em dentes decíduos, de maneira a avaliar a participação deste composto na melhora da morfologia de superfície e composição química da matriz dentinária após a aplicação deste biopolímero. 
Proposição 



\section{Proposição}

O presente estudo teve como objetivo avaliar o efeito da biomodificação da dentina por meio de aplicação do gel de quitosana a 2,5\% na microdureza e morfologia de superfície na dentina de dentes decíduos submetidos à indução de lesões de cárie artificiais, de maneira a simular a dentina afetada.

Os objetivos específicos foram:

1. Avaliar in vitro, da solução de quitosana a 2,5\% na microdureza subsuperficial;

2. Identificar e quantificar, por meio de espectroscopia eletrônica de análise química (EDS), os elementos químicos presentes nos diferentes grupos experimentais;

3. Avaliar in vitro, a estrutura superficial da dentina por meio de análise qualitativa da estrutura utilizando como método a microscopia eletrônica de varredura. 

Material e Métodos 



\section{Material e Métodos}

\section{Delineamento Experimental}

O fator estudado foi a biomodificação da dentina em dois níveis: aplicação de gel de quitosana a $2.5 \%$ e sem biomodificação. O delineamento experimental foi realizado em blocos completos casualizados, onde as variáveis de resposta foram: 1) análise quantitativa $(\mathrm{KNH})$ da microdureza da subsuperfície $(\mathrm{n}=10) ; 2)$ análise do percentual atômico de Cálcio $(\mathrm{Ca})$ e Fósforo $(\mathrm{P})$, bem como a relação $\mathrm{Ca} / \mathrm{P}$ de cada grupo por meio de Espectroscopia Eletrônica de Análise Química (EDS) $(n=3) ; 3)$ análise qualitativa da morfologia da superfície por meio de Microscopia Eletrônica de Varredura (MEV) $(n=3)$.

\section{Seleção dos dentes}

Foram selecionados 60 molares decíduos hígidos advindos do Biobanco de Dentes da Faculdade de Odontologia de Ribeirão Preto - USP, após aprovação do estudo pelo Comitê de Ética em Pesquisa da Faculdade de Odontologia de Ribeirão Preto - USP (CAAE no 57839116.9.0000.5419 - Anexo 1). Inicialmente, os mesmos foram limpos com auxílio de cureta tipo Gracey e foram submetidos à profilaxia com pedra-pomes e água, utilizando para tanto escovas de Robinson montadas em contra-ângulo em baixa rotação. Posteriormente, os dentes foram examinados macroscopicamente com auxílio de uma lupa estereoscópica (Leica Microsystems, Wetzlar, Alemanha) em aumento de 20x para detectar possíveis alterações estruturais. Os dentes foram, então, armazenados em água destilada à temperatura de $4^{\circ} \mathrm{C}$ até $\mathrm{o}$ início dos experimentos.

\section{Preparo da amostra}

Os dentes decíduos que ainda apresentavam raízes foram seccionados transversalmente na junção amelocementária utilizando para tanto disco diamantado montado em máquina de corte (Isomet 1000, Buehler, Alemanha).

As coroas dos dentes decíduos foram, então, polidas com uso de Politriz giratória (DP-9U2; Struers S/A, Copenhagen, Dinamarca), sendo tal procedimento realizado sob refrigeração à água com lixas de carbeto de silício de granulações 280 
e 1200 (Buehler Ltc., Lake Bluff, IL, USA), de maneira que todo o esmalte foi removido. Após este procedimento, as superfícies dentinárias foram avaliadas em lupa esteroscópica, com aumento de $20 \times$ para assegurar que todo o esmalte foi removido. Na sequência, as coroas dentais foram seccionadas longitudinalmente no sentido mésio-distal utilizando disco diamantado série $15 \mathrm{LC}$ de 0,3 $\mathrm{mm}$ de espessura montado em máquina de corte (Isomet 1000; Buehler, Alemanha), sob refrigeração, resultando assim em 2 fragmentos para cada coroa seccionada medindo $7 \times 3 \times 3 \mathrm{~mm}$ de dentina da face oclusal cada um.

Uma vez obtidos os fragmentos, estes foram devidamente fixados em matrizes de teflon utilizando cera fundida, de maneira tal que as superfícies dentinárias permaneceram voltadas para o meio externo. Os espécimes, então, receberam polimento final das superfícies dentinárias expostas com pasta de alumina

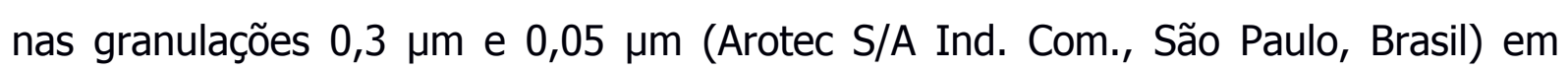
feltro polidor (ATM, Altenkirchen, Alemanha) e sob refrigeração. Finalizada esta etapa, os fragmentos foram armazenados em tubos cônicos de $5 \mathrm{~mL}$ (Eppendorf Tube $^{\circledR} 5.0 \mathrm{~mL}$, Merck KGaA, Darmstadt, Germany) com água destilada a $4^{\circ} \mathrm{C}$.

\section{Grupos experimentais}

Após o preparo das amostras, os espécimes foram devidamente alocados em grupos experimentais, conforme descrito na Figura 1. 
Figura 1 - Fluxograma Experimental.

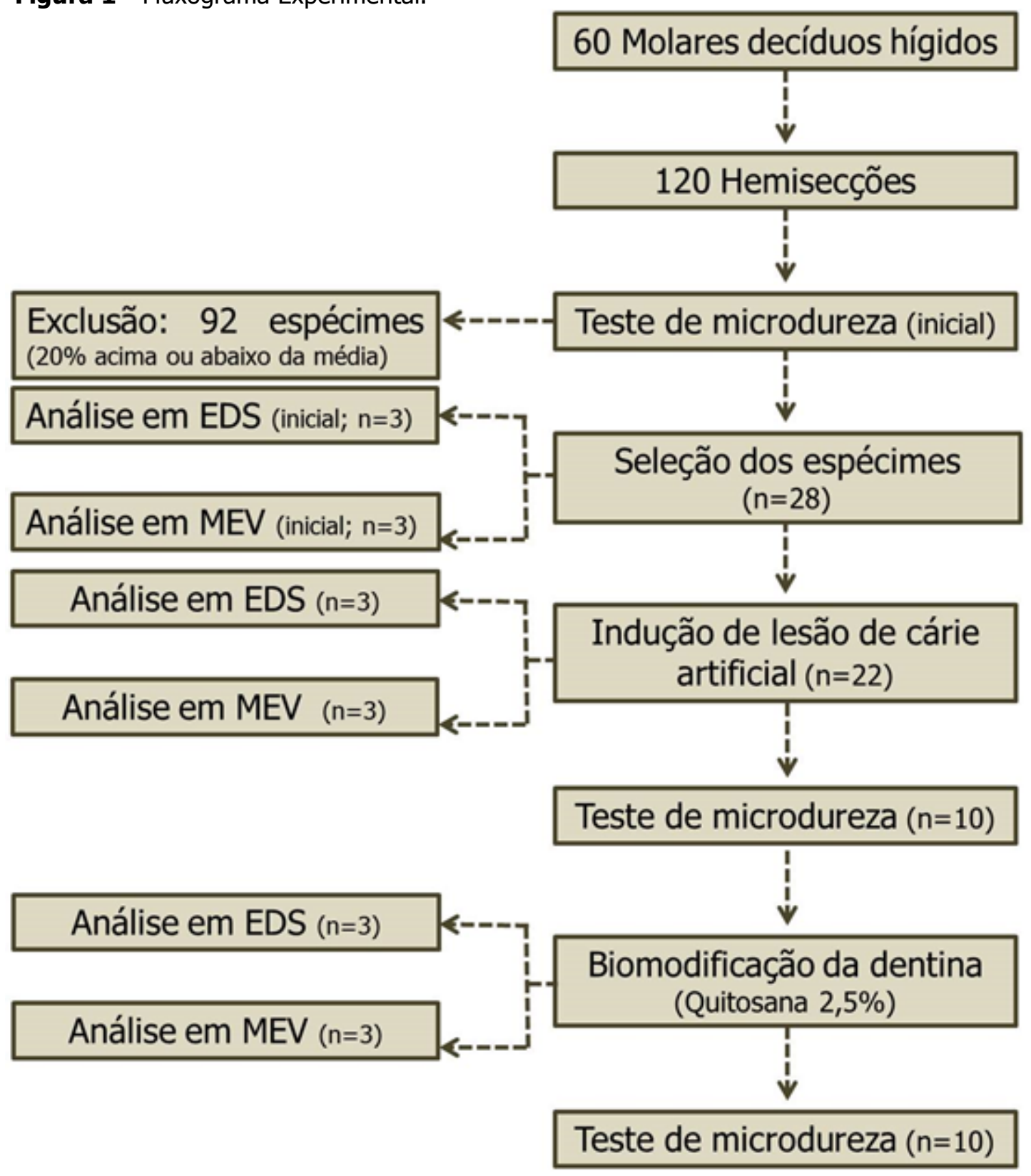

Após hemissecção dos 60 molares decíduos hígidos, conforme descrito previamente, um total de 120 espécimes foram obtidos e submetidos ao teste de microdureza inicial. Deste total, 28 espécimes foram selecionados para realização dos experimentos tendo como base o valor médio de microdureza de todos os espécimes. Deste total de 28 espécimes selecionados, 6 foram destinados à análise em EDS $(n=3)$ e MEV $(n=3)$. Após indução química de lesões de cárie, outros 6 espécimes foram destinados à análise em $\operatorname{EDS}(n=3)$ e $\operatorname{MEV}(n=3)$, sendo 10 espécimes destinados à análise de microdureza. Após a biomodificação da dentina com gel de quitosana a 2,5\%, outros 6 espécimes foram destinados à análise em 
EDS $(n=3)$ e MEV $(n=3)$, enquanto os outros 10 espécimes foram novamente submetidos à análise da microdureza.

\section{Preparo do gel de Quitosana a 2,5\%}

O gel de quitosana a $2,5 \%$ utilizado no presente estudo foi preparado no Laboratório de Pesquisas em Dentística do Departamento de Odontologia Restauradora da FORP-USP, utilizando para tanto 2,5 gramas de quitosana (SigmaAldrich, Saint Louis, MO, EUA) de baixo peso molecular (75-85\% de desacetilação) (Chung et al., 2016), a qual foi adicionada, lentamente, a $100 \mathrm{~mL}$ de solução de ácido acético 1\%, sob agitação magnética (Marconi Equip. Lab. Ltda, Piracicaba, SP, Brasil) durante $20 \mathrm{~min}$ (tempo suficiente para solubilizar o polissacarídeo). Para evitar a agregação das partículas e elevar o pH da solução ( $\mathrm{pH}=4,3)$, foi adicionado $1 \mathrm{~mol} / \mathrm{L}$ de solução NaOH (Daood et al., 2013; Fawzy et al., 2013).

\section{Análise Quantitativa (KHN) da Microdureza da Subsuperfície Dentinária}

Para análise da microdureza, os fragmentos de dentina seccionados conforme descrito previamente, foram posicionados em matriz de teflon com cera fundida e auxílio de paralelômetro e polidos em Politriz giratória refrigerada (Buehler, Chicago,EUA). O polimento foi feito com lixas de granulação \#1200 para obter uma superfície perfeitamente lisa e sem irregularidades superficiais, sendo tal polimento finalizado com pastas de alumina 0,3 e 0,05 $\mu \mathrm{m}$ (Struers A/S, Copenhagen, Dinamarca) em feltro polidor. Após o polimento, todas as hemi-secções foram submetidas ao teste de padronização das amostras em relação aos valores de microdureza das superfícies dentais correspondentes. Para tanto, foram realizadas três leituras na lateral dos fragmentos (subsuperfícies) distantes $30 \mu \mathrm{m}$ da superfície e $100 \mu \mathrm{m}$ uma da outra no microduromêtro HMV-2000 (Shimadzu Corporation, Kyoto, Japão), conforme ilustrado na Figura 2 (Hara et al., 2003) com penetrador de diamante para dureza Knoop (KHN) e carga estática de 10 gf aplicada por 15 segundos (de Siqueira Mellara et al., 2014). A média das três medidas foi utilizada como o valor de microdureza do fragmento, sendo que os fragmentos que apresentaram valor médio $20 \%$ superior ou inferior ao valor da média geral de todos os fragmentos serão descartados (De Menezes et al., 2007). Após indução da 
lesão de cárie, foi efetuada uma nova leitura dos valores de microdureza, bem como após o tratamento com gel de quitosana a 2,5\%, sendo estas realizadas conforme descrito previamente. A média das três medidas efetuadas foi utilizada como o valor de microdureza do fragmento após a indução da lesão de cárie, sendo o valor obtido comparado aos valores posteriormente obtidos com o tratamento com o gel de quitosana a 2,5\%. A aplicação do gel de quitosana a 2,5\% preparada foi realizada com auxílio de seringa, recobrindo toda a dentina e permaneceu na superfície por 1 minuto (Stamford-Aranaud et al., 2010) O gel foi aplicado de maneira a recobrir toda a superfície dentinária por um minuto. Após este tempo, os espécimes foram lavados com água destilada por 15 segundos e secos em papel absorvente, de maneira a remover os excessos de água provenientes da lavagem (Curylofo-Zotti et al., 2017).

Figura 2 - Representação esquemática de análise da microdureza na subsuperfície dos espécimes.

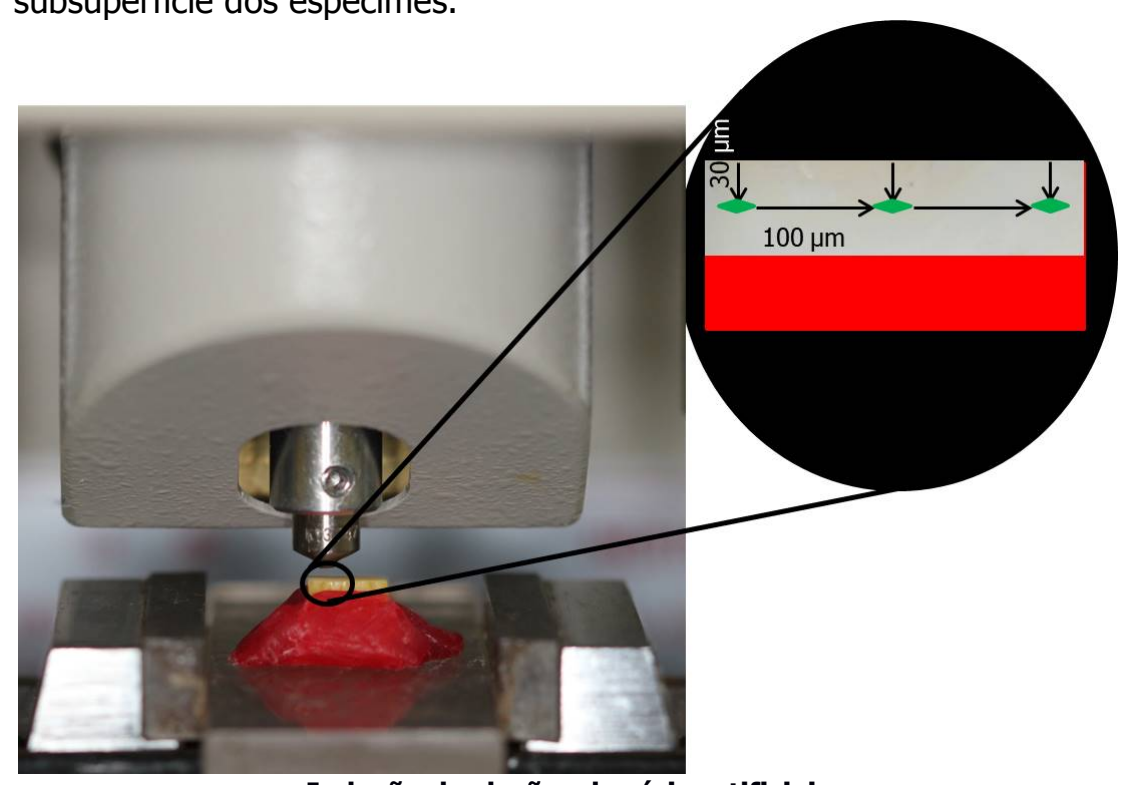

Indução das lesões de cárie artificiais

Para indução das lesões de cárie artificiais em dentina foi utilizado o protocolo previamente descrito por Marquezan at al., 2009, o qual utilizou a ciclagem do $\mathrm{pH}$ através do uso de duas soluções: uma desmineralizante e uma remineralizante.

A solução desmineralizante foi composta por $2 \mathrm{mM}$ de $\mathrm{CaCl}_{2}, 2,2 \mathrm{mM}$ de $\mathrm{NaH}_{2} \mathrm{PO}_{4}$ e $50 \mathrm{mM}$ de ácido acético com pH ajustado para 4,8. A solução remineralizante, por outro lado, foi constituída por 1,5 mM de $\mathrm{CaCl}_{2}, 0,9 \mathrm{mM}$ de 
$\mathrm{NaH}_{2} \mathrm{PO}_{4}$ e 0,15 $\mathrm{M}$ de $\mathrm{KCl}$ com pH ajustado para 7,0. Após o preparo, ambas soluções foram mantidas à temperatura de $4^{\circ} \mathrm{C}$.

Para indução das lesões de cárie artificiais propriamente ditas, as faces laterais de cada espécime foram protegidas com cera para escultura de prótese fixa (Kota Ind. E Com. Ltda., São Paulo, Brasil), de modo a manter exposta apenas a superfície dentinária. Sequencialmente, cada fragmento foi fixado individualmente em frascos de acrílico limpos, presos a embalagens plásticas com tampa. Cada espécime foi ciclado em $10 \mathrm{~mL}$ de cada solução: por $8 \mathrm{~h}$ foram mantidos em solução desmineralizante e por $16 \mathrm{~h}$ em solução remineralizante. Este procedimento foi realizado por um período de 14 dias em temperatura ambiente.

\section{Espectroscopia Eletrônica de Análise Química (EDS)}

Foram utilizados um total de 18 fragmentos destinados à EDS e MEV $(n=3)$, distribuídos aleatoriamente em 3 grupos (dentina hígida, dentina desmineralizada e dentina biomodificada com gel de quitosana a 2.5\%).

Após a indução de lesão de cárie artificial, foi realizada a biomodificação da superfície dentinária com gel de quitosana a 2,5\%. Como já citado, o gel foi aplicado de maneira a recobrir toda a superfície dentinária por um minuto. Após este tempo, os espécimes foram lavados com água destilada por 15 segundos e secos em papel absorvente, de maneira a remover os excessos de água provenientes da lavagem (Curylofo-Zotti et al., 2017).

A leitura por meio de EDS se baseia na emissão de energia proveniente de átomos e íons excitados para identificação e quantificação dos elementos químicos presentes em uma amostra. com detector de Espectrometria de Energia Dispersiva (EDS) acoplado (EVO 50; Carl Zeiss, Cambridge, Inglaterra) pertencente ao Laboratório de Microscopia Eletrônica de Varredura do Departamento de Química da Faculdade de Filosofia Ciências e Letras, Ribeirão Preto, SP e as porcentagens atômicas de Cálcio (Ca), Fósforo (P) presentes na superfície, bem como a relação $\mathrm{Ca} / \mathrm{P}$, foram determinadas. Para tal análise, foi utilizado um aumento de $300 \times$, utilizando uma distância de trabalho (wd) de 8,5 mm e voltagem de aceleração do feixe de elétrons de 20,00 kV e detector de comprimento químico BSD. 


\section{Microscopia Eletrônica de Varredura (MEV) da Superfície Dentinária}

Para análise em Microscopia Eletrônica de Varredura $(n=3)$, os espécimes foram imersos em solução de glutaraldeído a 2,5\% em tampão de cacodilato de sódio a 0,1 M, com pH ajustado para 7,4 (Merck KGaA, Darmstadt, D-64293, Alemanha) por um período de 12 horas. Após este período, os mesmos foram lavados em água destilada por 1 hora (3 lavagens com duração de 20 minutos cada uma) e secos com papel absorvente. Sequencialmente, os espécimes foram desidratados em séries crescentes de etanol (Labsynth Ltda., Diadema, SP, Brasil): 25\% (20 minutos), 50\% (20 minutos), 75\% (20 minutos), 95\% (30 minutos) e 100\% (60 minutos). Após secagem dos espécimes em papel absorvente, os mesmos foram imersos em hexametildisilazano (HDMS - Merck KgaA, Darmstadt, D-64293, Alemanha) por 10 minutos em capela. Após este período os fragmentos foram secos em papel absorvente e fixos em stubs com fita dupla-face de carbono, cobertos com fina camada de carbono e liga ouro-paladium em aparelho de metalização à vácuo (Bal-Tec AG,Balzers, Liechtenstein) e levados ao Microscópio Eletrônico de Varredura (EVO 50; Carl Zeiss, Cambridge, Inglaterra) do Departamento de Química da Faculdade de Filosofia Ciências e Letras de Ribeirão Preto-USP, onde foi realizada a varredura de toda superfície dentinária e, em seguida, fotografadas as áreas mais representativa de cada grupo em aumento de $1000 \times$.

A análise descritiva das características da superfície da dentina dos grupos foi realizada por 1 examinador cego, devidamente calibrado e que não participou da fase experimental. Durante a análise, o examinador era cego a todas as informações relativas aos grupos testados.

O examinador recebeu um conjunto completo de fotomicrografias (Ampliação de 1000x) e avaliou uma área correspondente a aproximadamente $60 \times 40 \mu \mathrm{m}$. As legendas de cada fotomicrografia foram cobertas para que o mesmo não soubesse a qual grupo pertencia cada amostra avaliada. A análise morfológica da superfície dentinária foi baseada nas características dentinárias estabelecidas em estudos anteriores que utilizaram dentes decíduos (Nör et al., 1997; Marquezan et al., 2009). Foram considerados os seguintes itens para análise da morfologia de superfície: contagem de túbulos dentinários que permaneceram parcial ou completamente obliterados, a condição da dentina peritubular na região de abertura dos túbulos 
dentinários (removida ou intacta) e topografia da dentina intertubular (rugosa/lisa/desmineralizada/superfície irregular ou regular).

\section{Análise estatística}

Os resultados obtidos foram submetidos à análise exploratória seguindo os conceitos clássicos de estatística. A homogeneidade de variância e distribuição normal das curvas do modelo matemático para a variável microdureza foram avaliadas quantitativamente por meio de teste de Shapiro-Wilk, utilizando para tanto, o programa estatístico SPSS versão 2.5 (IBM $^{\circledR}$ SPSS $^{\circledR}$ Statistics). Por apresentar distribuição normal, os dados foram sequencialmente avaliados por meio de teste paramétrico one-way ANOVA de medidas repetidas. A análise dos dados para EDS foi efetuada por meio de teste não paramétrico de Kruskal-Wallis seguido pelo ajuste dos valores de significância pela correção de Bonferroni para múltiplos testes, bem como por meio de estatística descritiva dos dados obtidos. 
Resultados 



\section{Resultados}

\section{Análise Quantitativa (KHN) da Microdureza da Subsuperfície Dentinária}

A Figura 3 mostra os intervalos de confiança (IC 95\%) para a microdureza da subsuperfície dentinária obtida em três momentos: na dentina hígida, na dentina desmineralizada (indução química de lesão de cárie) e após a biomodificação da dentina desmineralizada com gel de quitosana a 2,5\%.

Os intervalos do grupo dentina hígida e dentina desmineralizada não se sobrepõem, o que indica diferença entre os referidos grupos e, portanto, redução da microdureza da superfície dentinária após indução química de lesões de cárie. 0 mesmo pôde ser observado entre os grupos dentina hígida e dentina desmineralizada e biomodificada com gel de quitosana a 2,5\%. Por outro lado, houve intersecção dos intervalos entre o grupo dentina desmineralizada e dentina desmineralizada modificada com o gel de quitosana.

Figura 3 - Intervalos de confiança (IC 95\%) das medidas de microdureza.

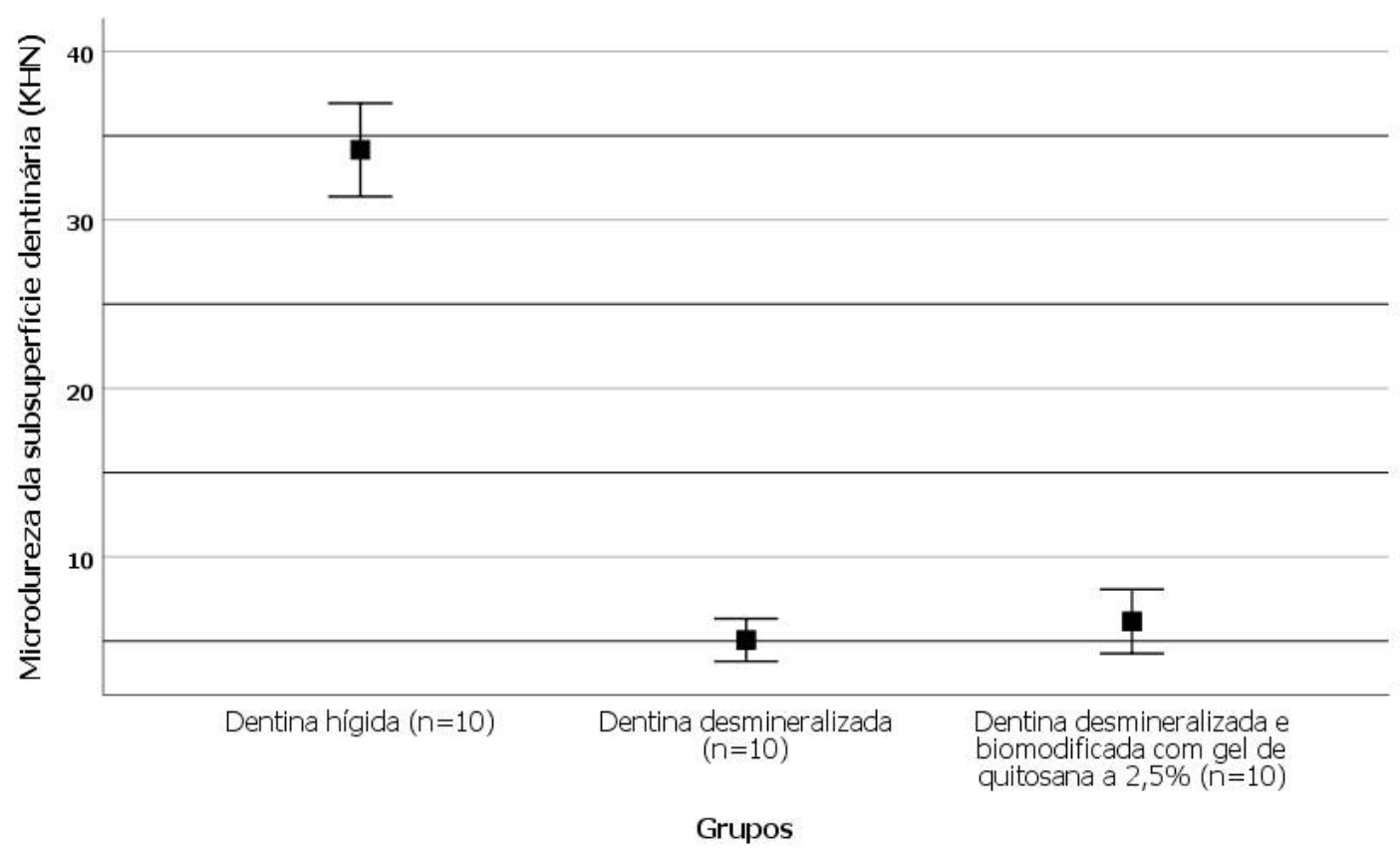

A indução química de lesões cariosas resultou na redução da microdureza da dentina $(p<0,001)$. Na comparação entre biomodificação ou não da dentina desmineralizada com gel de quitosana a 2,5\%, o valor médio de microdureza da dentina residual apresentou um sutil aumento após a biomodificação, porém não resultou em diferença estatisticamente significante $(p=0,339)$ (Tabela 1$)$. 
Tabela 1 - Média (desvio-padrão) e intervalo de confiança (limite inferior e limite superior) da microdureza da subsuperfície dentinária $(\mathrm{n}=10)$.

\begin{tabular}{lcccc}
\hline \multicolumn{1}{c}{ Grupos } & \multicolumn{3}{c}{ Intervalo de Confiança (95\%) } \\
\cline { 2 - 5 } \multicolumn{1}{c}{ Média } & DP & Limite Inferior & Limite Superior \\
\hline Dentina Hígida & 34,160 & 3,875 & 31,387 & 36,933 \\
Dentina Desmineralizada & $5,058^{*}$ & 1,772 & 3,790 & 6,326 \\
Dentina Biomodificada & $6,165^{*}$ & 2,658 & 4,264 & 8,067 \\
\hline
\end{tabular}

* indica diferença com grupo dentina hígida; ${ }^{*}$ indica diferença entre grupo dentina desmineralizada e dentina biomodificada (Teste Bonferroni com comparação por Método Pairwise; $p<0,05$ ).

\section{Espectroscopia Eletrônica de Análise Química (EDS) da Superfície Dentinária}

Os diferentes grupos apresentaram diferenças estatisticamente significantes com relação aos níveis de $\mathrm{Ca}, \mathrm{P}$, bem como na relação $\mathrm{Ca} / \mathrm{P}$ após análise por EDS $(p<0,027)$ (Tabela 2).

Tabela 2 - Teste não-paramétrico da Espectroscopia Eletrônica de Análise Química .

\begin{tabular}{lrrr}
\hline & Ca & $\mathbf{P}$ & Ca/P \\
\cline { 2 - 4 } H de Kruskal-Wallis & 7,200 & 7,200 & 7,200 \\
gl & 2 & 2 & 2 \\
Significância Sig. &, 027 &, 027 &, 027 \\
a. Teste Kruskal Wallis & & & \\
\hline *indica diferença entre grupos & $(p<0,05)$. Valores de significância foram ajustados pela
\end{tabular}
correção de Bonferroni para múltiplos testes.

A comparação entre os diferentes grupos analisados, porém, revelou que a porcentagem atômica do elemento cálcio apresentou diferenças estatisticamente significantes entre o grupo de dentina hígida e dentina biomodificada $(p<0,022)$, 0 que indica que após a perda do referido elemento através do processo de desmineralização o mesmo não foi recuperado após a biomodificação da dentina. Portanto, não houve reposição de cálcio na superfície da dentina desmineralizada e biomodificada com gel de quitosana a 2,5\% a níveis próximos daqueles encontrados na dentina hígida (Tabela 3).

Tabela 3 - Comparação entre grupos da porcentagem atômica (\% at.) do elemento cálcio (Ca). Erro padrão e significância ajustada pela correção de Bonferroni.

\begin{tabular}{lcc}
\hline Comparação entre grupos - \% at. P & EP & Sig. Ajust. \\
\hline Dentina hígida - Dentina desmineralizada & 2,236 & 0,539 \\
Dentina hígida - Dentina Biomodificada & 2,236 & $0,022 *$ \\
\hline
\end{tabular}


Um quadro semelhante pôde ser observado com relação à porcentagem atômica de fósforo presente nas amostras dos grupos analisados, porém em relação inversamente proporcional ao cálcio. A dentina biomodificada apresentou porcentagem atômica do referido elemento superior quando comparada ao grupo de dentina hígida, o que confirma, portanto, a perda de cálcio também observada. Contudo, a biomodificação da dentina desmineralizada não demonstrou diferença estatisticamente significante quando comparada ao grupo com dentina desmineralizada e sem biomodificação (Tabela 4).

Tabela 4 - Comparação entre grupos da porcentagem atômica (\% at.) do elemento fósforo (P). Erro padrão e significância ajustada pela correção de Bonferroni.

$\begin{array}{cc}\text { EP } & \text { Sig. Ajust. } \\ 2,236 & 0,539 \\ 2,236 & 0,022^{*}\end{array}$

*indica diferença entre grupos $(p<0,05)$. Valores de significância foram ajustados pela correção de Bonferroni para múltiplos testes.

Dessa forma, foi possível constatar que a relação Ca/P presente nas amostras também apresentou diferenças estatisticamente significantes apenas entre o grupo de dentina desmneralizada e biomodificada e dentina hígida, o que corrobora com o descrito até o presente momento (Tabela 5).

Tabela 5 - Comparação entre grupos da relação Ca/P. Erro padrão e significância ajustada pela correção de Bonferroni.

\begin{tabular}{lcc}
\hline Comparação entre grupos - Relação Ca/P & EP & Sig. Ajust. \\
\hline Dentina hígida - Dentina desmineralizada & 2,236 & 0,539 \\
Dentina hígida - Dentina Biomodificada & 2,236 & $0,022^{*}$ \\
Dentina desmineralizada - Dentina Biomodificada & 2,236 & 0,539 \\
\hline
\end{tabular}

*indica diferença entre grupos $(p<0,05)$. Valores de significância foram ajustados pela correção de Bonferroni para múltiplos testes.

Apesar de a análise estatística não apontar diferenças estatisticamente significantes, deve-se levar em consideração a natureza das amostras e o $n$ de seus grupos representativos. Como é possível observar na Figura 4, apesar de o teste estatístico não apontar diferenças estatisticamente significantes, é possível observar tendência à diferenças estatisticamente significantes entre os três grupos analisados no referente à porcentagem atômica de cálcio, bem como em relação à porcentagem 
atômica de fósforo (Figura 5) e a relação Ca/P (Figura 6), o que demonstra tendência à redução nos níveis de Ca tanto no grupo de dentina desmineralizada quanto biomodificada em relação ao gruo controle, bem como entre ambas, e o inverso em relação aos níveis de fosfato nas amostras.

Figura 4 - Intervalos de Confiança (IC 95\%) para porcentagem atômica (\%at.) de Cálcio.

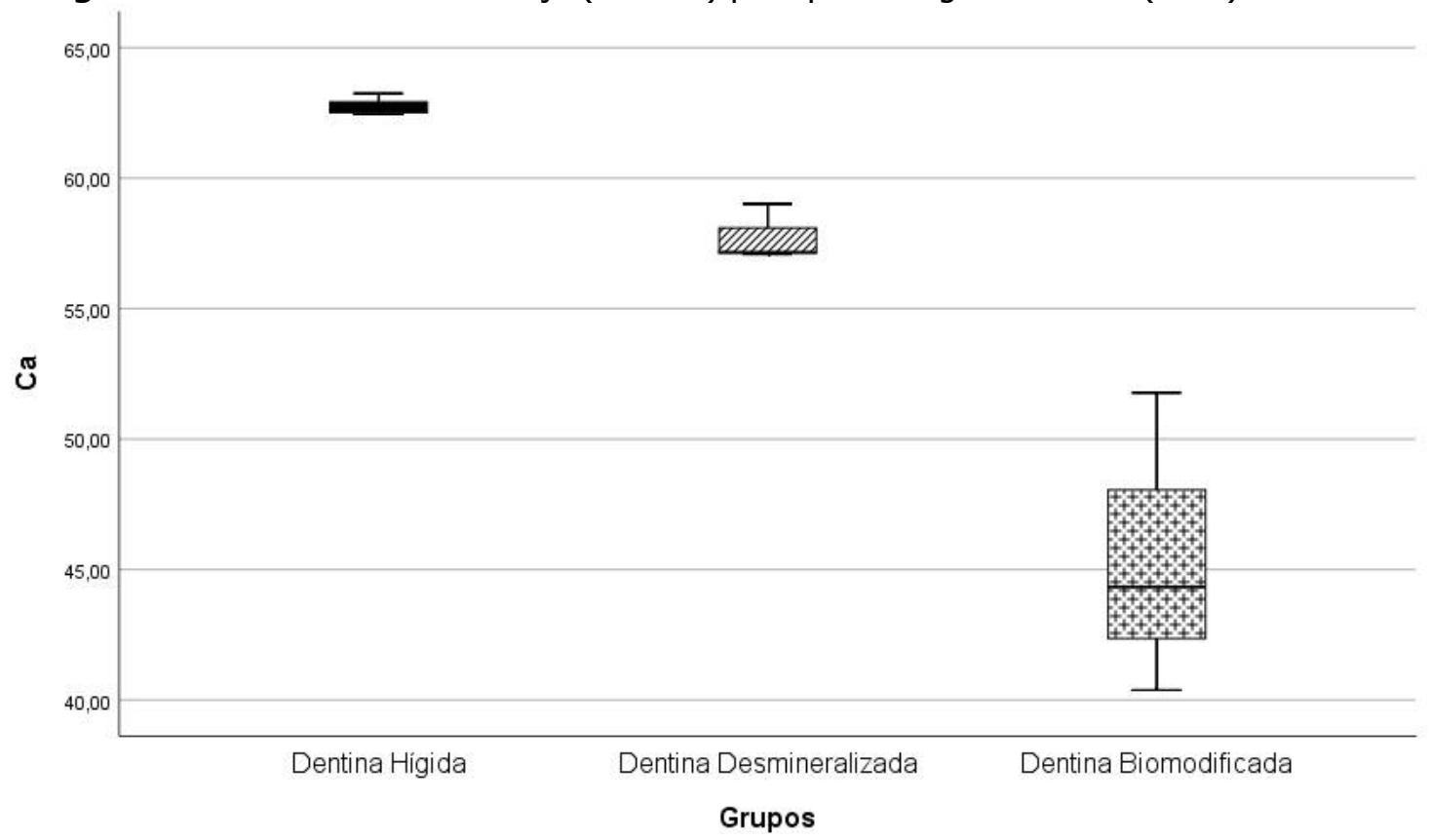

Figura 5 - Intervalos de Confiança (IC 95\%) para porcentagem atômica (\%at.) de Fósforo.

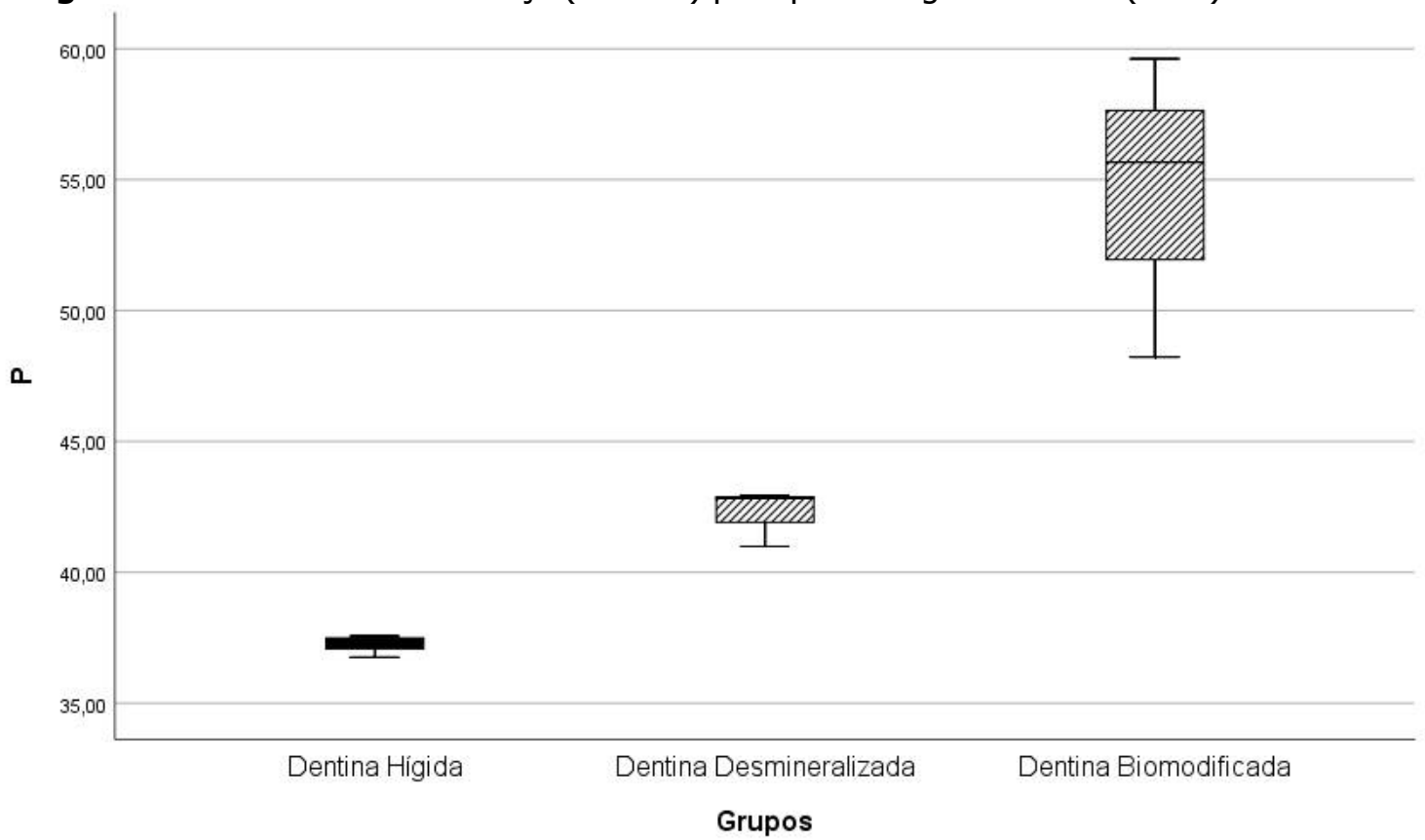


Figura 6 - Intervalos de Confiança (IC 95\%) para relação cálcio/fósforo (Ca/P).

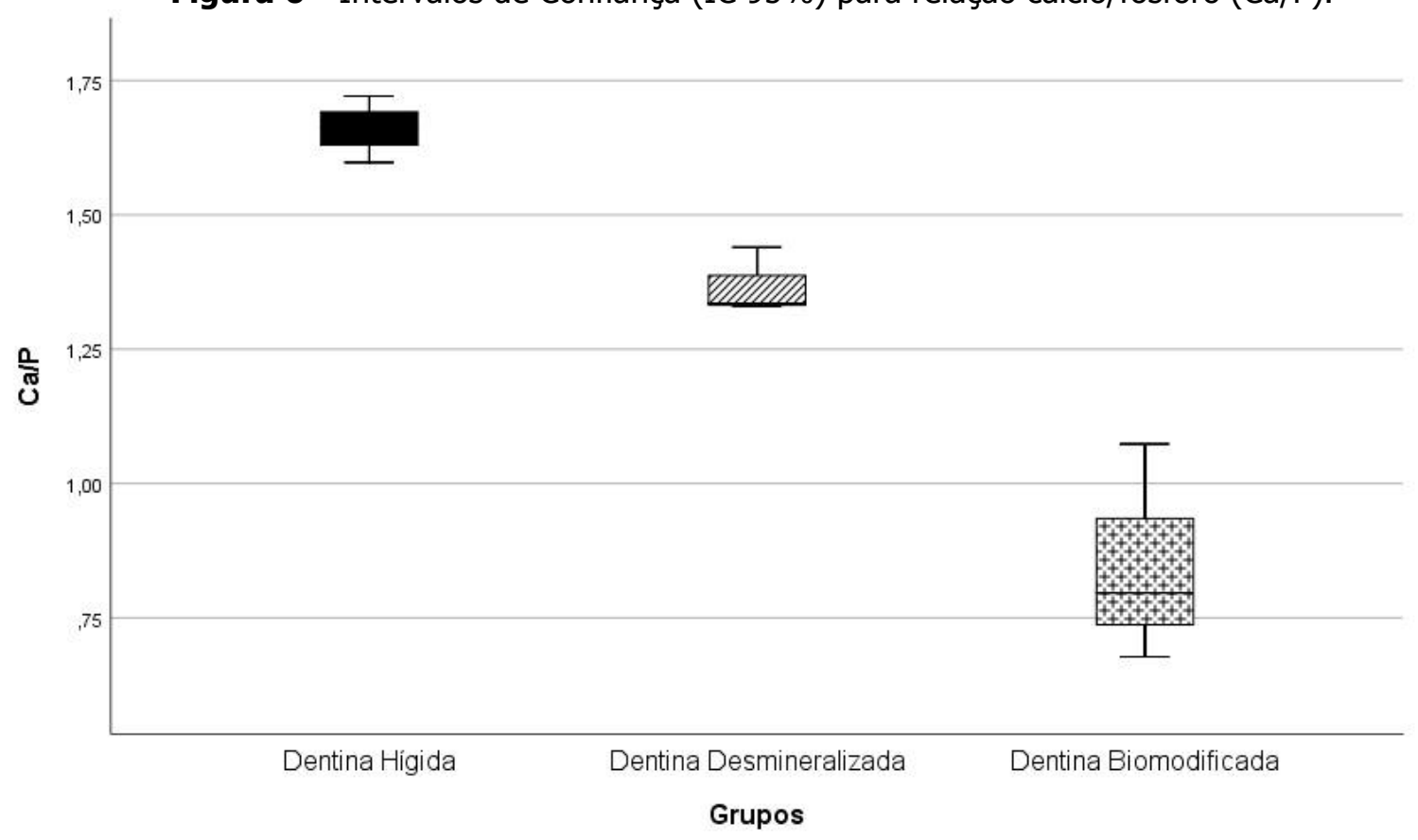

Portanto, devemos considerar que, apesar do apontado em números absolutos, é possível constatar que a indução química de lesão de cárie (dentina desmineralizada) culminou em uma perda de cálcio de $7,98 \%$, quando comparada ao grupo de dentina hígida (controle). Por sua vez, a biomodificação da dentina por meio da aplicação de gel de quitosana a 2,5\% gerou uma perda de cálcio de 21,22\% quando comparada ao grupo de espécimes que sofreram desmineralização por indução química. Assim sendo, a biomodificação da dentina desmineralizada não resultou em recuperação dos níveis de cálcio perdidos durante a indução química de lesão de cárie, ao contrário, induziu à maior perda do mesmo, sendo a porcentagem atômica de cálcio presente na dentina desmineralizada e biomodificada $27,5 \%$ menor quando comparada à quantidade presente na dentina hígida. $\mathrm{O}$ inverso foi observado em relação ao nível percentual de fósforo presente nas amostras, como já mencionado anteriormente. Foi observado um aumento de $13,44 \%$ do elemento citado nos espécimes desmineralizados quando comparado ao grupo controle, ao passo que o tratamento com a quitosana sob a forma de gel aumentou o nível de fósforo nas amostras em $29 \%$ em relação ao grupo de dentina desmineralizada sem biomodificação. Esses valores percentuais, dessa forma, representam $46,35 \%$ a mais da porcentagem atômica de fósforo na dentina biomodificada em relação à dentina hígida. Assim sendo, a relação cálcio/fósforo $(\mathrm{Ca} / \mathrm{P})$ se mostrou variada entre os 
grupos estudados. Essa relação reduziu 17,6\% no grupo de dentina desmineralizada quando comparada ao grupo de espécimes com dentina hígida, sendo essa redução de $37,93 \%$ no grupo submetido à biomodificação da dentina desmineralizada com aplicação do gel de quitosana a 2,5\% em relação ao grupo de dentina desmineralizada (Tabela 6).

Tabela 6 - Média (desvio-padrão) e intervalo de confiança (limite inferior e limite superior) da porcentagem atômica dos elementos $\mathrm{Ca}$ e $\mathrm{P}$ e sua relação $(\mathrm{Ca} / \mathrm{P})$ nos grupos estudados $(n=3)$.

Intervalo de Confiança

(95\%)

\begin{tabular}{|c|c|c|c|c|c|c|}
\hline Elemento & Grupos & $\begin{array}{c}\text { Média } \\
\text { ( } \% \text { at.) }\end{array}$ & DP & Mediana & $\begin{array}{l}\text { Limite } \\
\text { Inferior }\end{array}$ & Limite Superior \\
\hline \multirow{3}{*}{$\mathbf{C a}$} & Dentina Hígida & 62,759 & 0,430 & 62,759 & 61,69 & 63,827 \\
\hline & $\begin{array}{c}\text { Dentina } \\
\text { Desmineralizada }\end{array}$ & 57,750 & 1,091 & 57,167 & 55,04 & 60,46 \\
\hline & $\begin{array}{c}\text { Dentina } \\
\text { Biomodificada }\end{array}$ & 45,496 & 5,784 & 44,328 & 31,127 & 59,864 \\
\hline \multirow{3}{*}{$\mathbf{P}$} & Dentina Hígida & 37,241 & 0,430 & 37,41 & 36,172 & 38,309 \\
\hline & $\begin{array}{c}\text { Dentina } \\
\text { Desmineralizada }\end{array}$ & 42,249 & 1,091 & 42,833 & 39,539 & 44,959 \\
\hline & $\begin{array}{c}\text { Dentina } \\
\text { Biomodificada }\end{array}$ & 54,504 & 5,784 & 55,672 & 40,135 & 68,872 \\
\hline \multirow{3}{*}{$\mathrm{Ca} / \mathrm{P}$} & Dentina Hígida & 1,66 & 0,061 & 1,662 & 1,507 & 1,813 \\
\hline & $\begin{array}{c}\text { Dentina } \\
\text { Desmineralizada }\end{array}$ & 1,368 & 0,062 & 1,334 & 1,213 & 1,522 \\
\hline & $\begin{array}{c}\text { Dentina } \\
\text { Biomodificada }\end{array}$ & 0,849 & 0,203 & 0,796 & 0,344 & 1,354 \\
\hline
\end{tabular}

\section{Microscopia Eletrônica de Varredura (MEV) da Superfície Dentinária}

As imagens representativas de cada grupo estão dispostas na Figura 7. 
Figura 7. Fotomicrografias representativas da morfologia de superfície dos grupos experimentais: A. Dentina hígida. B. Dentina desmineralizada. C. Dentina desmineralizada e biomodificada com gel de Quitosana a 2,5\%. Imagens em aumento de $1000 \times$. D. Dentina desmineralizada e biomodificada com gel de Quitosana a 2,5\%. Imagem com aumento de $10000 \times$.
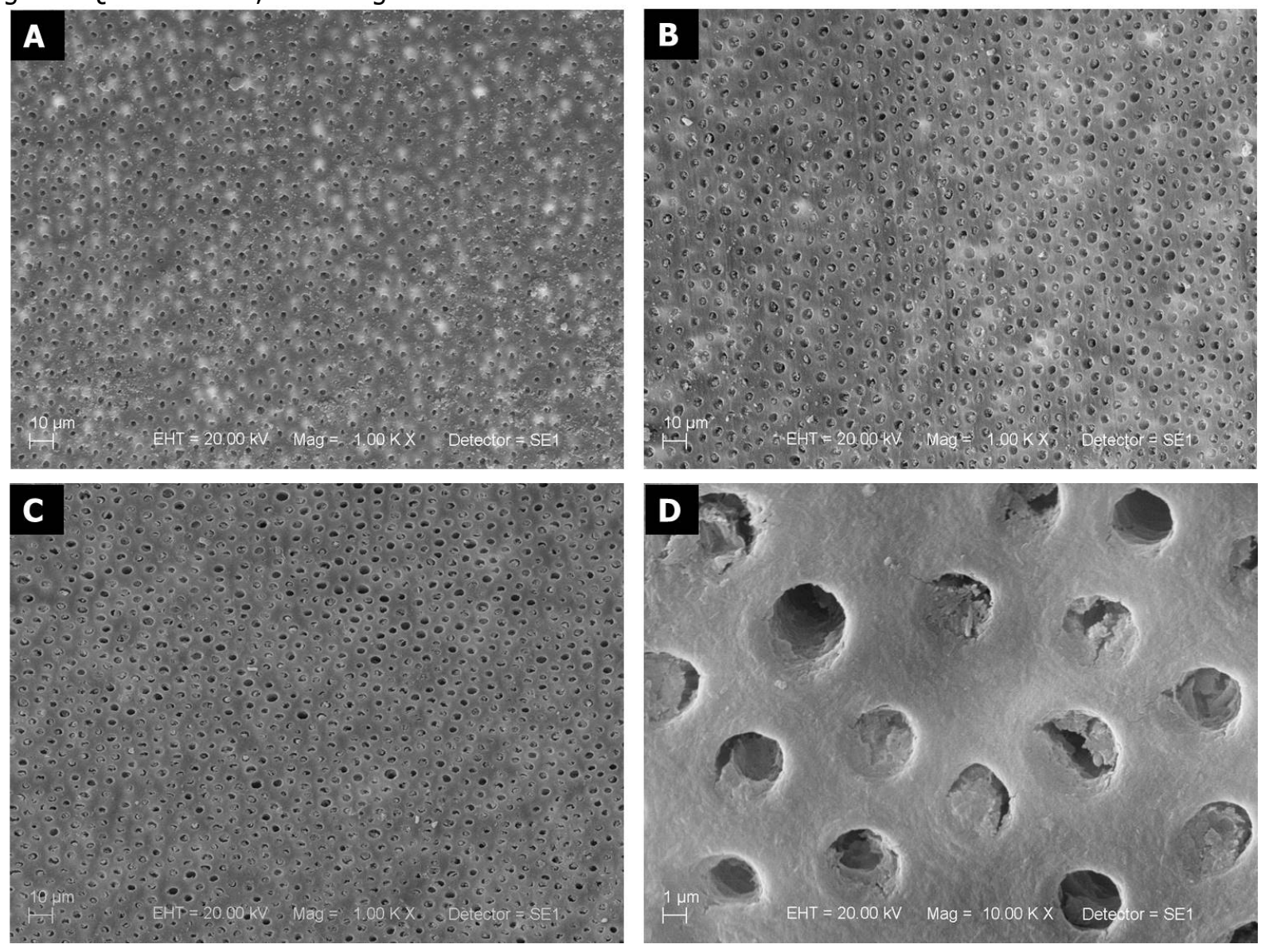

Como é possível observar na imagem representativa ao grupo de dentina hígida e, portanto, sem biomodificação, os túbulos dentinários se encontram abertos, ou seja, sem obliteração parcial ou total. Ainda, a dentina peritubular na região de abertura dos túbulos dentinários referente ao grupo de dentina hígida permaneceu intacta, sendo possível observar túbulos dentinários uniformemente distribuídos em toda superície, de tamanho semelhante e sem obliteração. A dentina intertubular apresenta superfície lisa e regular.

Por outro lado, a Figura 3-B revela diferenças topográficas relacionadas à dentina desmineralizada e sem biomodificação. Com relação ao número de túbulos dentinários parcial ou completamente obliterados, é possível observar que após a indução química de lesões de cárie e desmineralização da superfície dentinária, os túbulos quase que em sua totalidade apresentam certo grau de obliteração. A dentina peritubular neste grupo foi removida, culminando em túbulos dentinários de 
maior diâmetro, porém parcial ou completamente obliterados. A dentina intertubular apresentou superfície rugosa, desmineralizada e irregular.

A biomodificação da dentina desmineralizada revelou, porém, características topográficas interessantes. Como é possível observar na imagem representativa do grupo (Figura 3-C), o número de túbulos dentinários que estão parcial ou completamente obliterados ainda é expressivo, porém estas estruturas se apresentam com maior diâmetro. Por se tratar de dentina que foi desmineralizada, porém biomodificada, as imagens topográficas revelam uma superfície com ausência de dentina peritubular, porém superfície lisa e regular. Os túbulos dentinários apresentaram maior diâmetro de abertura, porém ainda se encontram parcial ou completamente obliterados. A Figura 3-D representa a dentina desmineralizada e biomodificada com gel de quitosana a 2,5\% em um aumento de 10000x. Apesar de os túbulos dentinários se encontrarem parcial ou completamente obliterados, como dito anteriormente, tal obliteração não se deu às custas da dentina parcialmente desmineralizada. Neste grupo que foi biomodificado com o polímero é possível constatar a presença de gel de quitosana no interior dos túbulos dentinários, o que nos permite concluir que a aplicação do biopolímero removeu a dentina parcialmente desmineralizada ao mesmo tempo em que o mesmo foi incorporado ao substrato dentinário ainda presente na superfície. 
Discussão 



\section{Discussão}

Há muito tempo se especula sobre o comportamento do tecido dentinário sadio e cariado. Marshall et al. (1997) já apontavam diferenças estruturais locais entre a dentina sadia e cariada, sendo que as mesmas são responsáveis por influenciar as propriedades do tecido dentinário e, consequentemente, impactar de maneira direta os tratamentos odontológicos preventivos e restauradores. É fato que a compreensão das propriedades mecânicas da dentina é importante para melhor prever como as tensões e esforços gerados sobre o tecido dentinário influenciam no comportamento da dentina em função de doenças, como a cárie dentária (Marshall et al., 1997).

Apesar de dentes decíduos e permanentes apresentarem tecido dentinário semelhante em relação ao conteúdo de fósforo $(P)$, conteúdo orgânico e inorgânico e microdureza, os teores de $\mathrm{Ca}$ e a relação cálcio/fósforo $(\mathrm{Ca} / \mathrm{P})$ são maiores em dentes permanentes, o que, apesar de tais diferenças, faz com que ambos os substratos apresentem comportamentos químicos e físicos semelhantes (Torres et al., 2018). Por isso, o presente estudo foi de grande importância, pois, compreender o comportamento mecânico e estrutural da dentina parcialmente desmineralizada e biomodificada em dentes decíduos é de grande relevância para condução do tratamento baseado nos conceitos e princípios da odontologia minimamente invasiva.

Com relação aos valores de microdureza foi possível constatar no presente estudo que a solução biomodificadora de quitosana, na forma em que foi preparada e aplicada, não resultou em aumento/recuperação de valores próximos ou iguais aos valores apresentados pela dentina hígida na dentina desmineralizada e biomodificada. É preciso deixar claro que a biomodificação da superfície dentinária com uso de quitosana não altera a composição química e estrutural da dentina afetada por cárie (Curylofo-Zotti et al., 2017), o que pode explicar, em parte, o motivo pelo qual este biopolímero não foi capaz de induzir um aumento significativo nos valores de microdureza na dentina desmineralizada. Além disso, o tratamento de uma superfície dental desmineralizada com quitosana age no processo de desmineralização por meio da inibição da perda mineral, porém sem surtir efeito 
significativo no processo de remineralização, de forma especial após 1 minuto de aplicação do biopolímero (Arnaud et al., 2010).

Além dessa constatação, foi possível verificar que o gel de quitosana a $2,5 \%$ não resultou em ganho mineral à estrutura dentinária parcialmente desmineralizada, e mais, culminou no aumento do diâmetro dos túbulos dentinários. Como exposto, o $\mathrm{pH}$ da solução final do gel de quitosana utilizado no presente estudo era de 4,3. É fato que o pH crítico do tecido dentinário, ou seja, o valor de $\mathrm{pH}$ no qual ocorre dissolução do tecido dentinário, é de 4,5, valor este que corresponde ao valor de pH responsável pela ativação de MMPs (Lussi et al., 2011). Portanto, diante do pH ácido inerente à própria solução biomodificadora foi possível observar superfície com ausência de dentina peritubular, porém lisa e regular, ao mesmo tempo em que os túbulos dentinários se apresentaram parcial ou totalmente obliterados e remoção da dentina parcialmente desmineralizada. É importante destacar que, mesmo em pH levemente básico ( $\mathrm{pH}$ 7.6), o que culmina em superfície dentinária recoberta por tecido desmineralizado e presença de túbulos dentinários parciamente cobertos, a quitosana pura apresental relevante na redução da perda mineral em dentina, muito em função do pH da solução, que influi diretamente na concentração final do biopolímero na mesma (Beltrame et al., 2018). Conforme observado no presente estudo, a dentina parcialmente desmineralizada apresentou maior porosidade e presença de túbulos dentinários parcial ou totalmente obliterados. De fato, a dentina parcialmente desmineralizada apresenta porosidade maior e obliteração de túbulos dentinários (Schwendicke, 2017), estas características somadas à presença de carga fracamente negativa e fracamente polar em decorrência da exposição de colágeno e ausência de conteúdo mineral sob a forma de cristais, o que the confere, portanto, baixo potencial de remineralização (Xu et al., 2011). Além disso, é válido lembrar que as metaloproteinases de matriz (MMPs) presentes na dentina podem ser ativadas em pH ácido e iniciar a degradação das fibrilas de colágeno (Beltrame et al., 2018). Metaloproteinases da matriz (MMPs) representam um grupo de mais de 25 enzimas que apresentam um importante papel na degradação da matriz orgânica dentinária (Jain e Bahuguna, 2015). Já foi demonstrado que a MMP-2, em tecido dentinário, é dinamicamente influenciada pelo $\mathrm{pH}$ do meio, sendo que o $\mathrm{pH}$ ácido ativa a forma latente desta enzima proteolítica (Amaral et al., 2018). 
No presente estudo, obteve-se uma superfície dentinária lisa e livre de fibrilas colágenas após a aplicação do biopolímero sobre a dentina parcialmente desmineralizada, provavelmente devido à ativação e atividade gelatinoílica das MMPs em função do $\mathrm{pH}$ da própria solução, o biopolímero aplicado foi incorporado ao substrato dentinário ainda presente na superfície, de modo a obliterar parcial ou totalmente os túbulos dentinários, cuja dimensão também sofreu modificações, tornando-se de maior diâmetro. Estas características se mostram interessantes, haja visto que o efeito erosivo sobre o substrato dentinário é mínimo (Silva et al., 2012) ao mesmo tempo em que permite a obtenção de uma superfície dentinária com características de grande importância ao tratamento restaurador minimamente invasivo. Como explicitado o pH da solução influencia de forma direta no grau de desmineralização da dentina, bem como no comportamento da mesma, por favorecer a formação de complexos hibridizados relativamente espessos (Ebrahimi et al., 2018), fato não observado em nossos resultados, muito provavelmente em função da presença do agente biomodificador.

Portanto, é possível compreender que a quitosana é capaz de remover o conteúdo orgânico, bem como a camada de smear layer na superfície dentinária por meio da interação desta com o substrato, o que inclui mecanismo de quelação de íons metálicos (Saker et al., 2012). Já foi demonstrado que a solução de quitosana promove redução da microdureza dentinária em função de sua capacidade quelante, sendo a solução solubilizada em ácido acético a de maior capacidade de quelar íons metálicos, o que inclui o cálcio (da Silva Mira et al., 2017), o que corrobora com os resultados apresentados no presente estudo, conforme já explicitado. Apesar de este mecanismo de quelação não estar completamente elucidado, há dois principais meios que explicam como este processo pode ocorrer (Pimenta et al., 2012; del CarpioPerochena et al., 2015). No primeiro modelo de quelação proposto, supõe-se que dois ou mais grupos amino da cadeia de uma cadeia quitosana se ligam a um mesmo íon metálico, como o cálcio, e por esta conformação química é conhecido como o modelo da ponte (Blair e Ho, 1981). Outro modelo proposto é o modelo do pendante, no qual apenas um grupo amino presente na estrutura química da quitosana mantém ligação com o íon metálico (Domard et al., 1987; Vold et al., 2003). É, portanto, esta característica quelante da solução de quitosana que tem 
demonstrado eficácia sobre o tecido dentinário, uma vez que atua de forma direta sobre a porção inorgânica da mesma (Silva et al., 2013). Esta capacidade conferida ao composto é comprovada em nossos resultados, pois ao mesmo tempo em que não se observa aumento da microdureza dos espécimes tratados, é possível observar uma estrutura dentinária lisa e com presença de túbulos dentinários maiores e sem indícios de tecido desmineralizado obliterando os mesmos, o que é indicativo de quelação dos íons cálcio livres em função da indução química de lesões de cárie.

É importante destacar que a quitosana, quando fosforilada gera imobilização covalente no colágeno da dentina desmineralizada e modifica a superfície da mesma, de modo a tornar a superfície do colágeno mais negativamente carregada, ao mesmo tempo em que reduz a energia livre entre colágeno e solução aquosa, haja visto que este composto tem a capacidade de introduzir grupos funcionais polares ao colágeno (Xu et al., 2011). O presente estudo, porém, revelou que a quitosana sob a forma de gel a 2,5\% tende a aumentar o percentual de desmineralização da superfície dentinária, apesar de não expressar uma diferença estatisticamente significante. Há de se convir que o agente biomodificador utilizado sob a forma de gel neste estudo não se apresentava como composto fosforilado. Como consequência, o gel de quitosana a 2,5\% utilizado como solução biomodificadora não reduziu a energia livre interfacial dentina-água. Dessa forma, não houve ligação covalente cruzada entre o biopolímero e o colágeno o que não permitiu a redução da energia livre interfacial dentina-água e, por conseguinte, não possibilitou a necleação de cristais minerais na superfície e a sequente remineralização da superfície dentinária (Wu e Nancollas, 1999; Xu et al., 2011). Além disso, deve-se lembrar que o processo de remodelamento da matriz dentinária requer a participação ativa do complexo dentino-pulpar e mecanismos fisiológicos mediados por metaloproteinases (MMPs), como já citado, e proteínas não colágenas, tais como a Sialoproteína óssea, que interceptam a relação entre fibrilas colágenas e hidróxiapatita. Dessa forma fica claro que o processo de remineralização é dinâmico e requer a presença de uma rede de colágeno bem estabelecida (Chibinski et al., 2016).

Conforme apresentado nos resultados, a aplicação do gel de quitosana promoveu uma sutil redução dos níveis de cálcio da dentina desmineralizada, quando 
comparada à dentina hígida. É válido apontar que o método utilizado para indução química das lesões de cárie utiliza soluções desmineralizante e remineralizante, como já fora citado anteriormente. Este método de indução de lesão de cárie química por ciclagem de $\mathrm{pH}$ promove desmineralização mais superficial da dentina de forma eficiente. Apesar de não simular a degradação do colágeno tal qual o método microbiológico, este método de indução da lesão de cárie se mostra efetivo em estudos cujo objetivo é obter um substrato semelhante à dentina afetada pela lesão de cárie, o qual corresponde ao objetivo do presente estudo (Marquezan et al., 2009). É esperado que a lesão de cárie dentária promova desmineralização dos tecidos dentários e gere a redução de seu conteúdo mineral, destacando a diminuição das concentrações de cálcio e fosfato (Magnus et al., 2013). Com a desmineralização da dentina em função da indução de lesão de cárie há deposição intratubular de cristais finos provenientes do próprio processo de desmineralização, pois este processo, por si, causa desmineralização tanto da dentina intertubular quanto peritubular, sendo maior na porção mais externa (Ogawa et al., 1983). Estes achados são comprovados no presente estudo e são facilmente observados nas imagens em Microscopia Eletrônica de Varredura. A presença deste conteúdo proveniente do próprio processo de desmineralização no interior dos túbulos dentinários pode explicar o motivo pelo qual não foi possível constatar diferenças estatisticamente significantes nas porcentagens atômicas de cálcio e fósforo, bem como a relação $\mathrm{Ca} / \mathrm{P}$ entre o grupo de dentina hígida e dentina desmineralizada, pois a presença dos referidos elementos foi mantida no interior dos túbulos dentinários, sendo detectada.

É válido destacar que o gel de quitosana a 2,5\% utilizado como solução biomodificadora da dentina foi obtido após diluição em solução de ácido acético. Já foi demonstrado que, independentemente do método de condicionamento utilizado, os dentes decíduos submetidos a protocolos que envolvam aplicação de soluções condicionantes ácidas, apresentam maior diâmetro dos túbulos dentinários em função de seu menor conteúdo mineral tanto na dentina peritubular quanto intertubular, o que reduz a quantidade de dentina presente no interior dos túbulos (de Los Angeles Moyaho-Bernal et al., 2018). Portanto, a aplicação do gel de quitosana a 2,5\% promoveu o aumento do diâmetro dos túbulos dentinários dada a 
natureza do pH da solução, conforme constatado, ainda, no presente estudo. É importante destacar que a dentina apresenta em sua composição uma parcela de água e, dessa forma, não é difícil compreender que a superfície desidratada em dentina desmineralizada representa um ponto crítico, haja visto que a desidratação prévia desta estrutura inerente à metodologia empregada pode resultar no colapso da superfície desmineralizada e na redução de profundidade real de dentina cariada, bem como da quantificação de mineral perdido (Angker et al., 2004).

Por outro lado, íons fosfato mantém interação eletrostática com a quitosana e, por este motivo, tendem a se difundir mais facilmente (Li et al., 2009). Li et al. (2009) avaliaram a capacidade de indução do processo de mineralização de hidrogel de quitosana e foi constatado que minerais Ca e P foram convertidos em apatita carbonatada, constituindo um meio de absorção de íons cálcio e fosfato via interação quelante (cálcio) ou eletrostática (fósforo), propriedade atribuída ao tratamento alcalino no qual o hidrogel fora submetido, o qual permitiu a conversão do fosfato de cálcio amorfo em apatita carbonatada de maneira tal que o hidrogel de quitosana constituiu o meio de reação dos minerais Cálcio e Fósforo. 


\section{Conclusão}





\section{Conclusão}

Com base nos resultados apresentados no presente estudo é capaz concluir que a aplicação do gel de quitosana a 2,5\% sobre o tecido dentinário parcialmente desmineralizado em dentes decíduos não foi capaz de aumentar significativamente os valores de microdureza, nem mesmo aumentar ou promover a recuperação dos níveis de cálcio. Contudo, a biomodificação da dentina gerou superfície dentinária lisa e com presença de túbulos dentinários de maior diâmetro, o que melhora as características topográficas para a realização de procedimentos restauradores adesivos. 

Referências 



\section{REFERÊNCIAS}

1. Ahmed TA, Aljaeid BM. Preparation, characterization, and potential application of chitosan, chitosan derivatives, and chitosan metal nanoparticles in pharmaceutical drug delivery. Drug Des Devel Ther. 2016;10:483-507.

2. Almeida Neves, A; Coutinho, E; Cardoso, MV; Lambrechts, P; Van Meerbeek, B. Current concepts and techniques for caries excavation and adhesion to residual dentin. J Adhes Dent 2011;13:7-22.

3. Amaral SFD, Scaffa PMC, Rodrigues RDS, Nesadal D, Marques MM, Nogueira FN, Sobral MAP. Dynamic Influence of $\mathrm{pH}$ on Metalloproteinase Activity in Human Coronal and Radicular Dentin. Caries Res. 2018;52(1-2):113-8.

4. Angker L, Nockolds C, Swain MV, Kilpatrick N. Quantitative analysis of the mineral content of sound and carious primary dentine using BSE imaging. Arch Oral Biol. 2004; 49(2):99-107.

5. Angker L, Swain MV, Kilpatrick N. Micro-mechanical characterisation of the properties of primary tooth dentine. J Dent. 2003;31(4):261-7.

6. Arnaud TM, de Barros Neto B, Diniz FB. Chitosan effect on dental enamel deremineralization: an in vitro evaluation. J Dent. 2010;38(11):848-52.

7. Banerjee A, Frencken JE, Schwendicke F, Innes NPT. Contemporary operative caries management: consensus recommendations on minimally invasive caries removal. $\mathrm{Br}$ Dent J. 2017 Aug 11;223(3):215-222.

8. Banerjee, A; Kellow, S; Mannocci, F; Cook, RJ; Watson, TF. An in vitro evaluation of microtensile bond strengths of two adhesive bonding agents to residual dentine after caries removal using three excavation techniques. J Dent 2010;38:480-489.

9. Banerjee, A. Minimal intervention dentistry: part 7. Minimally invasive operative caries management: rationale and techniques. Br Dent J 2013;214:107-111.

10. Banerjee A, Sherriff M, Kidd EAM, Watson TF. A confocal microscopic study relating the autofluorescence of carious dentine to its microhardness. Br Dent J. 1999; 187(4):20610 .

11. Bedran-Russo AK, Pauli GF, Chen SN, McAlpine J, Castellan CS, Phansalkar RS, Aguiar TR, Vidal CM, Napotilano JG,Nam JW, Leme AA. Dentin biomodification: strategies, renewable resources and clinical applications. Dent Mater. 2014;30(1):62-76.

12. Beltrame APCA, Suchyta D, Abd Alraheam I, Mohammed A, Schoenfisch M, Walter R, Almeida ICS, Souza LC, Miguez PA. Effect of Phosphorylated Chitosan on Dentin Erosion: An in vitro Study. Caries Res. 2018 Mar 6;52(5):378-386.

13. Benjamin R M. Oral health: The silent epidemic. Public Health Rep. 2010; 125: 158159. 
14. Blair HS, Ho TC. Studies in the adsorption and diffusion of ions in chitosan. J Chem Technol Biotechnol. 1981;31:6-10.

15. Casagrande L, Seminario AT, Correa MB, Werle SB, Maltz M, Demarco FF, Araujo FB. Longevity and associated risk factors in adhesive restorations of young permanent teeth after complete and selective caries removal: a retrospective study. Clin Oral Investig. 2016; [Epub ahead of print].

16. Chandy $T$, Sharma CP. Chitosan-as a biomaterial. Biomater Artif Cells Artif Organs. 1990;18:01-24.

17. Chibinski AC, Wambier L, Reis A, Wambier DS. Clinical, mineral and ultrastructural changes in carious dentin of primary molars after restoration. Int Dent $\mathrm{J}$. 2016;66(3):150-7.

18. Costa AR, Garcia-Godoy F, Correr-Sobrinho L, Naves LZ, Raposo LHA, de Carvalho FG, Sinhoreti MAC, Puppin-Rontani RM. Influence of Different Dentin Substrate (CariesAffected, Caries-Infected, Sound) on Long-Term $\mu$ TBS. Braz Dent J. 2017; 28(1):16-23.

19. Curylofo-Zotti FA, Tanta GS, Zucoloto ML, Souza-Gabriel AE, Corona SAM. Selective removal of carious lesion with Er:YAG laser followed by dentin biomodification with chitosan.Lasers Med Sci. 2017;32(7):1595-1603.

20. Cury JA, Tenuta LMA, Serra MC. Paradigms in Teaching Cariology. In: Fernandes CP (org). A world class dentistry. FDI 2010 Brazil. São Paulo: Santos; 2010. 374p.

21. da Silva Mira PC, Souza-Flamini LE, da Costa Guedes DF, Da Cruz-Filho AM.Evaluation of the chelating effect of chitosan solubilized in different acids. J Conserv Dent. 2017;20(5):297-301.

22. Debnath A, Kesavappa SB, Singh GP, Eshwar S, Jain V, Swamy M, Shetty P. Comparative evaluation of antibacterial and adhesive properties of chitosan modified glass ionomer cement and conventional glass ionomer cement: an in vitro study. J Clin Diagn Res. 2017; 11(3):ZC75-ZC78.

23. del Carpio-Perochena A, Bramante CM, Duarte MA, de Moura MR, Aouada FA, Kishen A. Chelating and antibacterial properties of chitosan nanoparticles on dentin. Restor Dent Endod. 2015 Aug;40(3):195-201.

24. de Los Angeles Moyaho-Bernal M, Contreras-Bulnes R, Rodríguez-Vilchis LE, RubioRosas $\mathrm{E}$. Changes in deciduous and permanent dentinal tubules diameter after several conditioning protocols: In vitro study.Microsc Res Tech. 2018; doi: 10.1002/jemt.23048. [Epub ahead of print].

25. De Menezes M, Turssi CP, Faraoni-Romano JJ, Serra MC. Susceptibility of bleached enamel and root dentin to artificially formed caries-like lesions. Am J Dent. 2007;20(3):173-6.

26. de Siqueira Mellara T, Palma-Dibb RG, de Oliveira HF, Garcia Paula-Silva FW, NelsonFilho $P$, da Silva RA, da Silva LA, de Queiroz AM.The effect of radiation therapy on the mechanical and morphological properties of the enamel and dentin of deciduous teeth-an in vitro study. Radiat Oncol. 2014;9:30. doi: 10.1186/1748-717X-9-30. 
27. Domard A. pH and c.d. measurements on a fully deacetylated chitosan: application to CuII-polymer interactions. Int J Biol Macromol 1987; 9:98-104.

28. Ebrahimi M, Janani A, Majidinia S, Sadeghi R, Shirazi AS. Are self-etch adhesives reliable for primary tooth dentin? A systematic review and meta-analysis. J Conserv Dent. 2018; 21(3): 243-250.

29. Elhennawy K, Finke C, Paris S, Reda S, Jost-Brinkmann PG, Schwendicke F. Selective vs stepwise removal of deep carious lesions in primary molars: 12-Months results of a randomized controlled pilot trial.J Dent. 2018;77:72-77. doi: 10.1016/j.jdent.2018.07.011. Epub 2018 Jul 17.

30. Elsaka S, Elnaghy A. Effect of addition of chitosan to self-etching primer: antibacterial activity and push-out bondstrength to radicular dentin. J Biomed Res. 2012;26(4):28894.

31. Fawzy AS, Nitisusanta LI, Iqbal K, Daood U, Beng LT, Neo J. Chitosan/Riboflavinmodified demineralized dentin as a potential substrate for bonding. J Mech Behav Biomed Mater. 2013;17:278-89.

32. Fejerskov O. Changing paradigms in concepts on dental caries: consequences for oral health care. Caries Res 2004;38:182-191.

33. Fejerskov, $\mathrm{O}$, Larsen, $\mathrm{MJ}$. Demineralization and remineralisation: the key to understanding clinical manifestations of dental caries. In: Fejerskov, O, Nyvad, B, Kidd, E editors. Dental caries: the disease and its clinical management. 3rd ed. Oxford (UK): 2015;160-169.

34. Frencken JE, Peters MC, Manton DJ, Leal SC, Gordan VV, Eden E. Minimal Intervention Dentistry (MID) for managing dental caries - a review: report of a FDI task group. Int Dent J. 2012;62(5):223-43.

35. Fuentes V, Toledano M, Osorio R, Carvalho RM. Microhardness of superficial and deep sound human dentin. J Biomed Mater Res A. 2003;66(4):850-3.

36. Giacaman RA. Sugars and beyond. The role of sugars and the other nutrientes and their potential impacto on caries. Oral Dis. 2017. doi doi: 10.1111/odi.12778. [Epub ahead of print].

37. Hara AT, Queiroz CS, Paes Leme AF, Serra MC, Cury JA. Caries progression and inhibition in human and bovine root dentine in situ. Caries Res. 2003;37(5):339-44.

38. Hu Y, Du Y, Yang J, Tang Y, Li J, Wang X. Self aggregation and antibacterial activity of $\mathrm{N}$-acylated chitosan. Polymer. 2007; 48(11):3098-106.

39. Innes NP, Frencken JE, Bjørndal L, Maltz M, Manton DJ, Ricketts $D$, Van Landuyt K, Banerjee A, Campus G, Doméjean S, Fontana M, Leal S, Lo E, Machiulskiene V, Schulte A, Splieth C, Zandona A, Schwendicke F. Managing Carious Lesions: Consensus Recommendations on Terminology. Adv Dent Res. 2016;28(2):49-57.

40. Ifuku S. Chitin and chitosan nanofibers: preparation and chemical modifications. Molecules. 2014; 19(11): 18367-80. 
41. Jain A, Bahuguna R. Role of matrix metalloproteinases in dental caries, pulp and periapical inflammation: An overview. Oral Biol Craniofac Res. 2015 ;5(3):212-8.

42. Kishen A. Mechanisms and risk factors for fracture predilection in endodontically treated teeth. Endodont Top. 2006;13:57-83.

43. Kishen A, Shrestha S, Shrestha A, Cheng C, Goh C. Characterizing the collagen stabilizing effect of crosslinked chitosan nanoparticles against collagenase degradation. Dent Mater. 2016; pii: S0109-5641(16):30052-5.

44. Keyes PH. Recent advances in dental research: bacteriology. Int Dent J 1962;12:443464.

45. Lin $\mathrm{TH}$, Lin $\mathrm{CH}$, Pan TM. The implication of probiotics in the prevention of dental caries. Appl Microbiol Biotechnol. 2018;102(2):577-586.

46. Li B, Wang $Y$, Jia D, Zhou $Y$, Cai W. Mineralization of chitosan rods with concentric layered structure induced by chitosan hydrogel.Biomed Mater. 2009 Feb;4(1):015011. doi: 10.1088/1748-6041/4/1/015011.Epub 2008 Nov 20.

47. Lussi A, Schlueter N, Rakhmatullina E, Ganss C. Dental erosion - an overview with emphasis on chemical and histopathological aspects. Caries Res 2011; 45(suppl 1):212.

48. Macedo, GV; Yamauchi, M; Bedran-Russo, AK. Effects of chemical cross-linkers on caries-affected dentin bonding. J Dent Res 2009;88:1096-1100.

49. Machiulskiene V, Carvalho JC. Clinical Diagnosis of Dental Caries in the 21st Century: Introductory Paper - ORCA Saturday Afternoon Symposium, 2016. Caries Res. 2018;52(5):387-391.

50. Magnus L, Maltz M, Bavaresco C, Bastos LF, Hashizume LN. Biochemical composition of carious dentin and different layers of sound dentin. J Oral Sci.2013;55(2):133-137.

51. Marquezan M, Corrêa FN, Sanabe ME, Rodrigues Filho LE, Hebling J, Guedes-Pinto AC, Mendes FM. Artificial methods of dentine caries induction: A hardness and morphological comparative study. Arch Oral Biol. 2009;54(12):1111-7.

52. Marshall GW Jr, Marshall SJ, Kinney JH, Balooch M.The dentin substrate: structure and properties related to bonding.J Dent. 1997;25(6):441-58.

53. Mjör, IA. Dentin permeability: The basis for understanding pulp reactions and adhesive technology. 2009. Braz Dent J.; 20(1):3-16.

54. Mm J, Nk B, A P. Minimal Intervention Dentistry - A New Frontier in Clinical Dentistry. J Clin Diagn Res. 2014;8(7):ZE04-8.

55. Mobarak, EH; El-Badrawy, WH. Microshear bond strength of self-etching adhesives to caries-affected dentin identified using the dye permeability test. J Adhes Dent 2012;14:245-250.

56. Newbrum E. Cariology. 2nd ed. Baltimore: Williams \& Wilkins, 1983. 389p. 
57. Nör JE, Feigal RJ, Dennison JB, Edwards CA. Dentin bonding: SEM comparison of the dentin surface in primary and permanent teeth.Pediatr Dent. 1997;19(4):246-52.

58. O'Connell AC. The partial removal of carious tissue may arrest caries progression in primary teeth. J Evid Based Dent Pract. 2012;12(3):146-8.

59. Ogawa K, Yamashita Y, Ichijo T, Fusayama T. The ultrastructure and hardness of the transparent layer of human carious dentin. J Dent Res. 1983;62(1):7-10.

60. Patrulea V, Ostafe V, Borchard G, Jordan O. Chitosan as a starting material for wound healing applications. Eur J Pharm Biopharm. 2015;97(Pt B):417-26.

61. Periayah $\mathrm{MH}$, Halim AS, Saad AZ. Chitosan: A Promising Marine Polysaccharide for Biomedical Research. Pharmacogn Rev. 2016;10(19):39-42.

62. Philip N, Suneja B, Walsh LJ. Ecological Approaches to Dental Caries Prevention: Paradigm Shift or Shibboleth?. Caries Res. 2018;52:153-65.

63. Philip N, Suneja B, Walsh L. Beyond Streptococcus mutans. clinical implications of the envolving dental caries a etiological paradigms and its associated microbiome. $\mathrm{Br}$ Dent J. 2018b; 224(4):219-25.

64. Pimenta JA, Zaparolli D, Pécora JD, Cruz-Filho AM. Chitosan: effect of a new chelating agent on the microhardness of root dentin.Braz Dent J. 2012;23(3):212-7.

65. Ribeiro CC, de Oliveira Lula EC, da Costa RC, Nunes AM. Rationale for the partial removal of carious tissue in primary teeth. Pediatr Dent. 2012;34(1):39-41.

66. Rinaudo M. Chitin and chitosan: Properties and applications. Prog. Polym. Sci. 2006;31:603-632.

67. Saker S, Alnazzawi A, Özcan M.Adhesive strength of self-adhesive resins to lithium disilicate ceramic and dentin: effect of dentin chelating agents. Odontology. 2016 Jan;104(1):53-9.

68. Schwendicke F. Contemporary concepts in carious tissue removal: A review. J Esthet Restor Dent. 2017;29(6):403-8.

69. Silva Júnior ZS, Botta SB, Ana PA, França CM, Fernandes KP, Mesquita-Ferrari RA, Deana A, Bussadori SK. Effect of papain-based gel on type I collagen spectroscopy applied for microstructural analysis. Sci Rep. 2015;5:11448.

70. Silva PV, Guedes DF, Nakadi FV, Pécora JD, Cruz-Filho AM.Chitosan: a new solution for removal of smear layer after root canal instrumentation.Int Endod J. 2013;46(4):332-8.

71. Tangsadthakun C, Kanokpanont S, Sanchavanakit N, Pichyangkura R, Banaprasert T, Tabata Y, Damrongsakkul S. The influence of molecular weight of chitosan on the physical and biological properties of collagen/chitosan scaffolds. J Biomater Sci Polym Ed. 2007; 18(2):147-63. 
72. Thompson V, Craig RG, Curro FA, Green WS, Ship JA. Treatment of deep carious lesions by complete excavation or partial removal: A critical review. J Am Dent Assoc. 2008;139(6):705-12.

73. Torres CP, Miranda Gomes-Silva J, Menezes-Oliveira MAH, Silva Soares LE, Palma-Dibb RG, Borsatto MC. FT-Raman spectroscopy, $\mu$-EDXRF spectrometry, and microhardness analysis of the dentin of primary and permanent teeth. Microsc Res Tech. 2018;81(5):509-514.

74. Vold IMN, Vårum KM, Guibal E, Smidsrød O. Binding of ions to chitosan-selectivity studies. Carbohydr Polym. 2003;54:471-477.

75. Wu WJ, Nancollas GH. Kinetics and surface energy approaches to the crystallization of synthetic and biological calcium phosphates. Phosphorus Sulfur Silicon Relat Elem 1999; 144:125-128.

76. Xia W, Liu P, Zhang J, Chen J. Biologic activities of chitosan and chitooligosaccharides. Food Hydrocolloid. 2011;25(2):170-79.

77. Xu Z, Neoh KG, Lin CC, Kishen A. Biomimetic deposition of calcium phosphate minerals on the surface of partially demineralized dentine modified with phosphorylated chitosan. J Biomed Mater Res B Appl Biomater. 2011;98(1):150-9.

78. Younes I, Rinaudo M. Chitin and chitosan preparation from marine sources. Structure, properties and applications. Mar Drugs. 2015;13(3):1133-74. 